\title{
Auxin Signaling and Transport Promote Susceptibility to the Root-Infecting Fungal Pathogen Fusarium oxysporum in Arabidopsis
}

\author{
Brendan N. Kidd,, ${ }^{1,2}$ Narendra Y. Kadoo, ${ }^{1}$ Bruno Dombrecht, ${ }^{1}$ Mücella Tekeoğlu, ${ }^{1}$ Donald M. Gardiner, ${ }^{1}$ \\ Louise F. Thatcher, ${ }^{1}$ Elizabeth A. B. Aitken, ${ }^{2}$ Peer M. Schenk, ${ }^{2}$ John M. Manners, ${ }^{1}$ and Kemal Kazan ${ }^{1}$ \\ ${ }^{1}$ Commonwealth Scientific and Industrial Research Organization Plant Industry, Queensland Bioscience Precinct, St Lucia, \\ Queensland, 4067, and ${ }^{2}$ School of Biological Sciences, The University of Queensland, St Lucia, Queensland, 4072, Australia
}

Submitted 1 September 2010. Accepted 14 January 2011.

Fusarium oxysporum is a root-infecting fungal pathogen that causes wilt disease on a broad range of plant species, including the model plant Arabidopsis thaliana. Currently, very little is known about the molecular or physiological processes that are activated in the host during infection and the roles these processes play in resistance and susceptibility to $F$. oxysporum. In this study, we analyzed global gene expression profiles of $F$. oxysporum-infected Arabidopsis plants. Genes involved in jasmonate biosynthesis as well as jasmonate-dependent defense were coordinately induced by $F$. oxysporum. Similarly, tryptophan pathway genes, including those involved in both indole-glucosinolate and auxin biosynthesis, were upregulated in both the leaves and the roots of inoculated plants. Analysis of plants expressing the DR5:GUS construct suggested that root auxin homeostasis was altered during $F$. oxysporum infection. However, Arabidopsis mutants with altered auxin and tryptophan-derived metabolites such as indole-glucosinolates and camalexin did not show an altered resistance to this pathogen. In contrast, several auxin-signaling mutants were more resistant to $F$. oxysporum. Chemical or genetic alteration of polar auxin transport also conferred increased pathogen resistance. Our results suggest that, similarly to many other pathogenic and nonpathogenic or beneficial soil organisms, $F$. oxysporum requires components of auxin signaling and transport to colonize the plant more effectively. Potential mechanisms of auxin signaling and transport-mediated $F$. oxysporum susceptibility are discussed.

The fungal pathogen Fusarium oxysporum is the causative agent of the Fusarium wilt disease in many economically important plants such as cotton, banana, tomato, legumes, and

Current address for N. Kadoo: Plant Molecular Biology Group, Division of Biochemical Sciences, National Chemical Laboratory, Dr. Homi Bhabha Road, Pune, 411008, India.

Current address for B. Dombrecht: Ablynx, Technologiepark 4, 9052 Ghent, Belgium.

Current address for M. Tekeoglu: Ondokuz Mayis University, Department of Agricultural Biotechnology, Samsun, Turkey.

Corresponding author: K Kazan; Telephone (+61) 7-3214-2678; E-mail: kemal.kazan@csiro.au

* The $\boldsymbol{e}$-Xtra logo stands for "electronic extra" and indicates that five supplementary figures and two supplementary tables are published online. Figures 1 through 7 also appear in color online. commercial flowers. This soilborne pathogen enters the plant through the roots and, subsequently, colonizes the vascular tissue. Although most F. oxysporum strains are nonpathogens and survive either saprophytically in the soil or endophytically inside the plant tissue, some strains have developed pathogenicity toward certain hosts. Recent research has demonstrated that nonpathogenic strains of this fungus can become pathogenic by acquiring, through horizontal transfer, pathogenicity chromosomes from pathogenic strains (Ma et al. 2010). Plants infected with pathogenic isolates of $F$. oxysporum show severe developmental alterations such as stunting and wilting, followed by extensive chlorosis and necrosis on the leaves and eventual plant death. $F$. oxysporum is considered to be a "hemibiotroph" (Thaler et al. 2004) because the initial stages of infection by this pathogen are thought to be biotrophic whereas later stages of infection resemble the lifestyle of necrotrophic pathogens.

In contrast to leaf-infecting pathogens, relatively little is known about the molecular mechanisms employed by rootinfecting pathogens such as $F$. oxysporum and the nature of belowground defenses employed by the host plant to combat such pathogens (Edgar et al. 2006; Millet et al. 2010; Okubara and Paulitz 2005). The model plant Arabidopsis thaliana can also be infected by $F$. oxysporum (Berrocal-Lobo and Molina 2008; Dombrecht et al. 2006; Michielse and Rep 2009; van Hemelrijck et al. 2006). The availability of plentiful genetic and genomic resources in this plant species provides an excellent opportunity to identify molecular mechanisms involved in host resistance against $F$. oxysporum. Like many other plant species, resistance to F. oxysporum in Arabidopsis is inherited as a quantitative trait (Diener and Ausubel 2005). One quantitative trait locus contains an atypical resistance gene called RESISTANCE TO FUSARIUM OXYSPORUM1 (RFO1) that confers quantitative resistance against $F$. oxysporum (Diener and Ausubel 2005). RFOl encodes wall-associated kinase-like kinase 22 (WAKL22) but the potential mechanisms of RFO1mediated $F$. oxysporum resistance is currently unknown.

As one might expect, plant hormone-signaling pathways also play key roles in plant defense against $F$. oxysporum. Recent evidence shows that salicylic acid (SA) provides an increased resistance to this pathogen in Arabidopsis (Diener and Ausubel 2005; Edgar et al. 2006; Thatcher et al. 2009). Curiously, the jasmonate (JA)-signaling pathway plays both a positive and negative role in affecting $F$. oxysporum infection, the balance of which determines the eventual disease outcome. Transgenic overexpression of transcription factor genes acting positively (e.g., ERF1 and ERF2) on JA-responsive defense genes (e.g., 
PDF1.2) confers increased F. oxysporum resistance (BerrocalLobo et al. 2002; McGrath et al. 2005). Furthermore, transcription factors that act as negative regulators (e.g., ERF4, AtAF2, and MYC2) of JA-dependent defenses confer increased $F$. oxysporum susceptibility (Anderson et al. 2004; Delessert et al. 2005; McGrath et al. 2005). Interestingly, however, the Arabidopsis coil mutant, despite reduced JA-dependent defenses, shows strong resistance to $F$. oxysporum (Thatcher et al. 2009) and this has prompted a reassessment of the role played by JA in this host-pathogen interaction. The coil-mediated $F$. oxysporum resistance appears to be due to reduced levels of JA-induced senescence, which is exploited by the pathogen to cause disease symptoms (Thatcher et al. 2009). Further support for the suggestion that an increased senescence response exacerbates disease development has come from analysis of the cpr5/hys 1 mutant. This mutant has constitutively active defenses and increased senescence responses, and shows increased $F$. oxysporum susceptibility (Schenk et al. 2005). More recently, the PFT1 gene encoding the MED25 subunit of the plant mediator complex, which positively regulates the JA-responsive defense genes, has also been identified as an $F$. oxysporum susceptibility gene (Kidd et al. 2009). Similar to the coil mutant, the pft1 mutant shows reduced expression of JA-responsive genes but increased $F$. oxysporum resistance (Kidd et al. 2009). Finally, abscissic acid and its signaling pathway promote susceptibility to this pathogen (Anderson et al. 2004) while the roles of other hormone-signaling pathways, such as auxin, which has been implicated in the modulation of plant defense and resistance processes (Kazan and Manners 2009), is unknown.

In the current study, we analyzed the Arabidopsis transcriptome in response to infection with $F$. oxysporum to identify host-related processes that may affect $F$. oxysporum disease resistance. In addition to genes involved in JA biosynthesis and signaling, we found that tryptophan (Trp)-pathway genes involved in indole metabolism, including auxin and indole-3methyl-glucosinolate (IG) biosynthesis and metabolism, were upregulated by $F$. oxysporum, suggesting that infection by this pathogen may alter the auxin homeostasis of inoculated plants. Indeed, we show herein that inoculation of plant roots with $F$. oxysporum induced auxin-responsive DR5:GUS reporter gene activity. This prompted focus on the potential roles that host auxin biosynthesis, transport, and signaling would have on $F$. oxysporum resistance. No effect of exogenous auxin application or mutations or overexpressions of genes required for endogenous auxin biosynthesis on Fusarium spp. resistance could be found. In contrast, auxin-signaling and transport mutants showed increased disease resistance to $F$. oxysporum, suggesting that auxin signaling and transport promote susceptibility to this pathogen. Potential roles of auxin-mediated protein ubiquitination and auxin signaling or transport in promoting susceptibility to Fusarium wilt disease are discussed.

\section{RESULTS}

\section{F. oxysporum infection differentially regulates \\ SA- and JA-dependent defenses.}

In an effort to identify molecular mechanisms involved in $F$. oxysporum-Arabidopsis interactions, we first analyzed the expression patterns of well-known SA- and JA-responsive defense genes in both the leaves and the roots of F. oxysporuminoculated plants. Effects of the pathogen on host defense gene expression were assessed at 1 and 2 days after inoculation
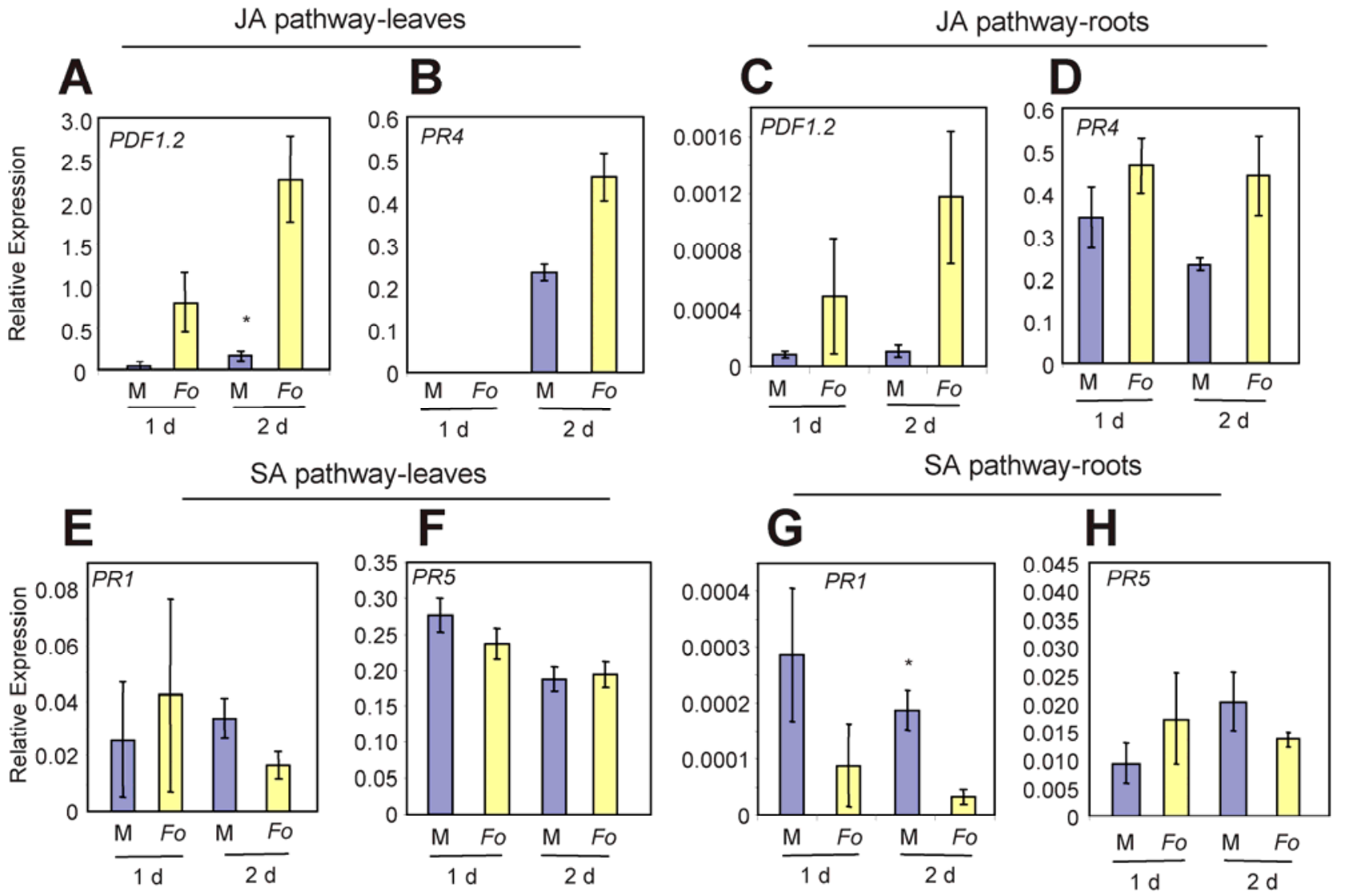

Fig. 1. Fusarium oxysporum-responsive defense gene expression in Arabidopsis. Expression of A through D, jasmonate (JA)-responsive PDF1.2 and PR4 (HEL) and $\mathbf{E}$ through $\mathbf{H}$, salicylic acid (SA)-responsive PR1 and PR5 genes in the roots and leaves of $F$. oxysporum-infected Arabidopsis plants 1 and 2 days following inoculations. Data are the average of three independent inoculation experiments with standard error. $\mathrm{M}=\mathrm{Mock} ;$ Fo $=$ Fusarium oxysporum. $*$ Significantly different from the treatment at $P<0.05$, using Student's $t$ test. 
when root invasion had occurred but there was little, if any, fungal colonization of the shoot. A clear induction of the JAresponsive genes $P D F 1.2$ and $P R 4$ (hevein-like [HEL]) in both roots and leaves was evident 2 days after inoculations (Fig. 1A to D). In contrast to JA-responsive defense genes, the expression of both of the SA-responsive defense genes, $P R 1$ and $P R 5$, was either nonresponsive or even repressed by $F$. oxysporum 2 days after inoculations (Fig. 1E to G). This suggests that $F$. oxysporum differentially regulates different defense responses during infection of Arabidopsis plants. We also noted that, relative to the reference $\beta$-ACTIN genes, the transcript levels of both groups of these defense genes in the roots were several orders of magnitude lower than those observed in the leaves (Fig. 1A to $\mathrm{H}$ ).

Given that SA- and JA-responsive defense genes are minimally expressed in the roots, we speculate that a substantial proportion of the defense response against this pathogen occurs preemptively in the leaves. Indeed, in contrast to the development of massive necrosis in the leaves of inoculated plants, which is scored to assess disease resistance, the colonization of Arabidopsis roots with $F$. oxysporum does not cause any visible necrosis on the roots (B. Kidd and K. Kazan, unpublished).

\section{F. oxysporum infection activates defense and developmental pathways in Arabidopsis.}

To globally assess gene expression after challenge by $F$. oxysporum, an Affymetrix microarray experiment was conducted. Because the experiments described above indicated that overall leaf transcripts levels were higher in leaves than roots, the array experiment used leaves only, and some genes selected as differentially expressed on the basis of the array results were subsequently tested on both roots and leaves using real-time quantitative reverse-transcription polymerase chain reaction (RT-QPCR). The Affymetrix chip experiments consisted of samples from four independent inoculation experiments (also independent from the ones shown in Figure 1), in which the roots of Arabidopsis plants were either inoculated with $F$. oxysporum or mock inoculated with water and the aboveground tissue was collected 2 days after inoculation for gene expression analysis. In these analyses, genes that showed a differential response between mock and $F$. oxysporum treatment $(P<0.05)$ were classified into functional groups using the DAVID database (Dennis et al. 2003). These analyses showed that genes belonging to defense response or immunity, Trp and indole metabolism, glucosinolate metabolism, aromatic amino acid metabolism, and lipid transport functional groups were overrepresented among the $479 F$. oxysporum-responsive Arabidopsis genes (Fig. 2; Supplementary Table S1). These main groups of genes altered by Fusarium spp. infection are briefly discussed below.

\section{JA-dependent defense genes.}

The defense or immunity functional category contained a number of defense-related genes and, in particular, a significant enrichment of JA-associated genes. As expected from the analysis shown in Figure 1, Fusarium spp. inoculation also induced other JA-dependent defense genes such as $C H I B, T H I$, LEC, and GERMIN-LIKE as well as PDF1.2 and PR4 (Fig. 2). The microarray data also revealed the induction of other JA-related genes such as those that encode JA biosynthesis enzymes (e.g., LOX, JMT, AOS, AOC, and OPR) as well as signaling proteins such as ATCHL1, a pathogen and JA-inducible chlorophyllase involved in the positive regulation of JA signaling (Kariola et al. 2005), and JA ZIM domain proteins JAZ2 and JAZ9 involved in negative regulation of JA signaling (Chini et al. 2007; Thines et al. 2007). In addition, transcription factor genes such as MYC2, ERF2, and ORA59 that are known to be involved in the regulation of JA-dependent defenses (Brown et al. 2003; Lorenzo et al. 2004; McGrath et al. 2005; Pré et al. 2008) were all induced by F. oxysporum (Fig. 2).

\section{Lipid transfer protein genes.}

Surprisingly, lipid transfer protein (LTP)-encoding genes, which have been associated with plant defense, showed reduced expression after Fusarium spp. inoculation. We identified 10 LTP (At2g38530, At5g59320, At5g59310, At3g53980, At1g12090, At2g37870, At2g13820, At3g22600, At4g33550, and At1g62510) that all showed reduced expression in the inoculated plants relative to mock-inoculated plants. Of these, three related LTP, LTP2 (At2g38530), LTP3 (At5g59320), and LTP4 (At5g59310), belong to the PR14 class of pathogenesisrelated (PR) proteins known to have antibiotic properties against the bacterial wilt pathogen Ralstonia solanacearum as well as $F$. solani and Plectosphaerella cucumerina (Hernández-Blanco et al. 2007; Segura et al. 1993). Recently, an LTP-like protein from tomato has been shown to be required for susceptibility to $F$. oxysporum f. sp lycopersici, the tomato-infecting strain of F. oxysporum (Krasikov et al. 2010). Whether the LTP proteins contribute to susceptibility to $F$. oxysporum in Arabidopsis is unknown. However, reduced expression of the LTP gene family could suggest a conserved mechanism to suppress these proteins to assist in the defense response of the plant. Determining the role of the LTP proteins in defense against $F$. oxysporum warrants further investigation.

\section{Genes involved in anthocyanin}

and aromatic amino acid biosynthesis.

We found induction of genes that encode an MYB transcription factor (MYB113) involved in the regulation of anthocyanin biosynthesis genes (Gonzalez et al. 2008), a UGT78D1-glycosyltransferase involved in flavonol glycoside biosynthesis (Jones et al. 2003), and anthocyanin 5-aromatic acyltransferase 1 (AACT1) involved in anthocyanin biosynthesis. F. oxysporuminoculated Arabidopsis plants often develop stress-related anthocyanin formation in their leaves, and the induction of these genes is consistent with this observation.

\section{Trp and indole biosynthesis and metabolism genes.}

The enzyme encoded by the ANTHRANILATE SYNTHASE $\alpha S U B U N I T 1$ ( $A S A 1)$ gene induced by this pathogen catalyzes the rate-limiting step of Trp synthesis (Bender and Celenza 2009) (Fig. 2). Similarly, PHOSPHORIBOSYLANTHRANILATE TRANSFERASE1 (PAT1), PHOSPHORIBOSYLANTHRANILATE ISOMERASE3 (PAI3), INDOLE-3-GLYCEROL PHOSPHATE SYNTHASE (IGPS), and TRYPTOPHAN SYNTHASE $\alpha$ CHAIN1 (TSAl), which encode enzymes that catalyze the subsequent enzymatic steps leading to the synthesis of Trp, were all induced by $F$. oxysporum (Fig. 2). In addition, we found that transcript levels of a number of other genes whose gene products function in Trp-dependent auxin and IG biosynthesis and metabolism were altered in response to infection. For instance, the expression of $C Y P 79 B 2$ and $C Y P 79 B 3$ were induced by $F$. oxysporum. The CYTOCHROME P450, FAMILY 79, SUBFAMILY B, and POLYPEPTIDE 2 and 3 enzymes encoded by these genes, respectively, convert Trp to indole-3-acetaldoxime (IAOx), a precursor of 3-indolacetic acid (IAA) and IG (Fig. 2) (Zhao et al. 2002). Also induced by pathogen infection is the expression of CYP83BI and $U G T 74 B 1$, which encode an oxime-metabolizing cytochrome P450 monooxygenase enzyme and a UDP-glucose:thiohydroximate S-glucosyltransferase, respectively (Fig. 2). These two enzymes are involved in the conversion of IAOx to IG (Grubb and Abel 2006) (Fig. 2). We found that the expression of the OBP2/AtDOF1.1 gene encoding a DOF family transcription factor regulating the expression of the abovementioned genes, 
CYP79B2, CYP79B3, and CYP83B1 (Skirycz et al. 2006), was also induced (Fig. 2). Also induced by $F$. oxysporum infection were the expression of the genes encoding nitrile specifier protein 5 (NSP5) and a GDSL-motif lipase with homology to the epithiospecifier (ESP)-modifier 1 (ESM1) protein. The two enzymes are involved in converting IG to nitriles and potentially toxic isothiocyanates, respectively (Burow et al. 2008; Grubb and Abel 2006). Previously, F. oxysporum was found to be more aggressive on the leaves of the Arabidopsis gsm1-1 mutant that lacks an isothiocyanate (Tierens et al. 2001). In addition, genes such as $M B P 1$ and $P B P 1$ functioning in IG metabolism were induced by $F$. oxysporum (Fig. 2). MBPI encodes myrosinase binding protein 1 and $P B P 1$ encodes a PYK10-binding protein1, a close homolog of PEN2 myrosi- nase required for reducing the root colonization by the endophytic fungus Piriformospora indica (Sherameti et al. 2008). Myrosinase-binding protein genes are also induced during infection of the roots by the pathogenic fungus Plasmodiophora brassicae (Devos et al. 2006; Siemens et al. 2006). Finally, we found that IAA-LEUCINE RESISTANT (ILR)-LIKE GENE 5 and 6 (ILL5 and ILL6, respectively) were induced. These genes encode two members of the Arabidopsis IAA-amino acid conjugate hydrolase subfamily involved in generating IAA from the hydrolysis of IAA-amino acid conjugates (Woodward and Bartel 2005). Together, these findings suggest that infection with $F$. oxysporum results in significant changes to plant defense, as well as the production of anthocyanin and downstream Trp metabolites such as IG and auxin.

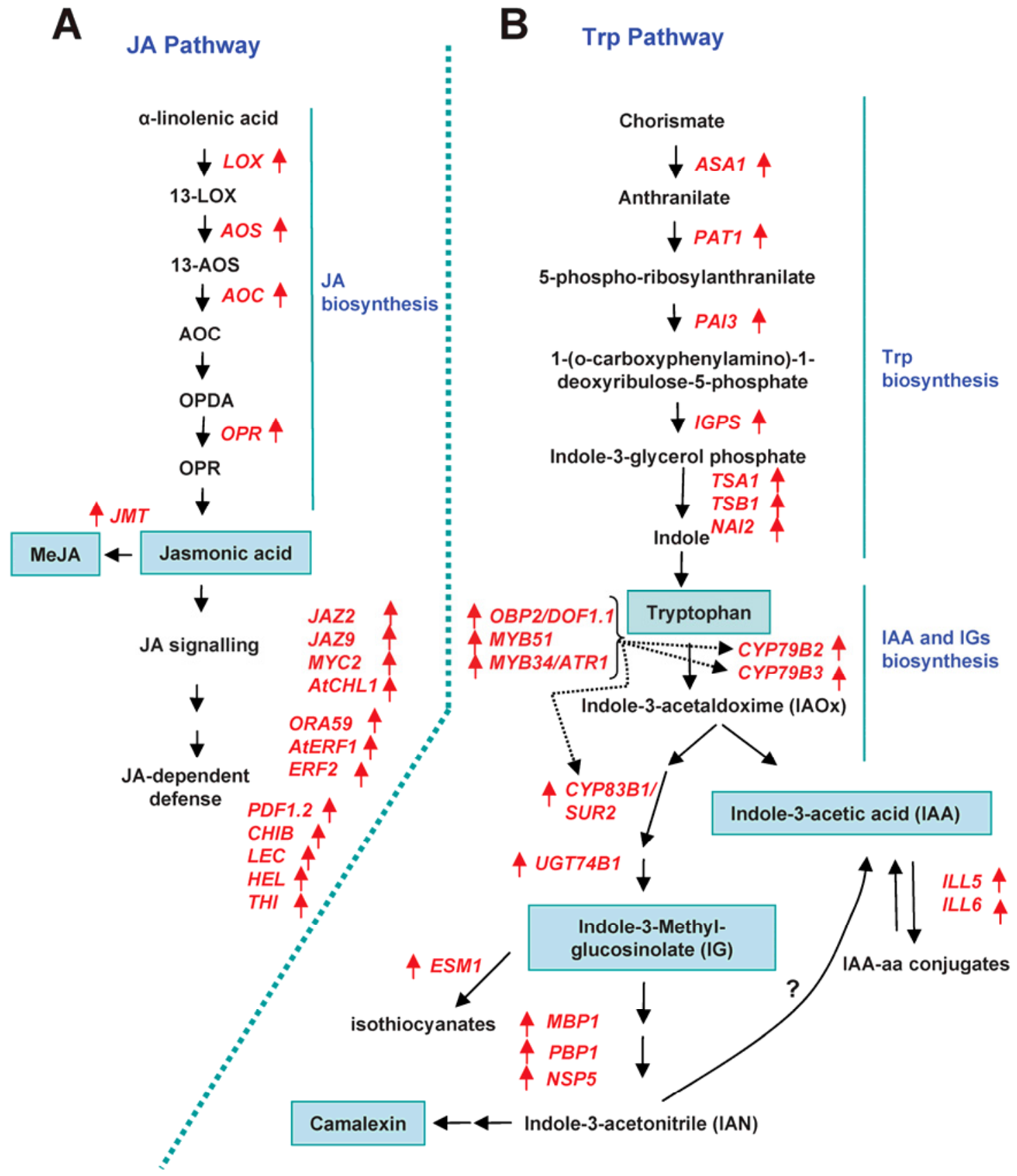

Fig. 2. Infection by Fusarium oxysporum coordinately induces genes involved in A, jasmonate (JA)-biosynthesis, signaling, and JA-dependent defense as well as B, tryptophan (Trp)-mediated 3-indolacetic acid (IAA) and indole-3-methyl-glucosinolate (IG) biosynthesis in the leaves of Arabidopsis plants inoculated with F. oxysporum. Red arrows indicate significant upregulation by $F$. oxysporum as detected by Affymetrix Gene chip analyses. Please note that upregulation of MYB51 and MYB54 is based on a separate experiment. Broken lines in B represent positive regulation of key genes in the pathway by the transcription factors indicated. Key metabolites generated are shown in the boxes. 


\section{F. oxysporum infection alters root auxin homeostasis.}

Of all the functional categories identified in the Affymetrix chip experiments, the Trp pathway was particularly significant because there was consistent induction of the genes encoding the majority of known biosynthetic enzymes in this pathway (Fig. 2). Therefore, in independent time-course inoculation experiments, we first confirmed the pathogen inducibility of a subset of Trp-pathway genes using RT-Q-PCR. Surprisingly, Trp-pathway genes were systemically upregulated in the leaves of inoculated plants as early as $3 \mathrm{~h}$ after inoculation (Supplementary Fig. S1). This time point is much earlier than the induction of JA- and repression of SA-responsive defense genes shown in Figure 1. In these experiments, we also found upregulation of ATR1/MYB34 and MYB51 genes in inoculated plants. These two transcription factors act as activators of genes involved in Trp-derived auxin and IG biosynthesis (Celenza et al. 2005; Gigolashvili et al. 2007).

In the root tissue, we also found increased expression of Trp-pathway genes after inoculation with $F$. oxysporum (Supplementary Fig. S2). Overall, the expression levels of the Trppathway genes were higher in the roots compared with the leaves, suggesting that there may be more Trp metabolism in the roots, and this is consistent with higher levels of IG found in Arabidopsis roots (van Dam et al. 2009). These findings provide additional support to the view that auxin and IG homeostasis are altered in both roots and shoots of $F$. oxysporuminoculated plants.

To test whether the induction of these genes in both leaves and roots during infection correlated with alterations in auxin homeostasis in inoculated plants, we generated a green fluorescent protein (GFP)-expressing fungal strain and used this to inoculate the roots of DR5:GUS plants. Inoculation experiments with the GFP-expressing strain showed that fungal hyphae were mostly associated with root tips and lateral root initials at the initial stages of the infection process (Fig. 3A to D). This was followed by the colonization of the whole root surface with superficial hyphae (not shown). An independent fungal transformant expressing red fluorescent protein (RFP) also showed similar colonization patterns (Supplementary Fig. S3). The DR5:GUS construct, which uses highly active auxin-responsive promoter elements to drive $\beta$-glucuronidase (GUS) expression (Ulmasov et al. 1997), is commonly used as a reporter to monitor the changes in tissue auxin homeostasis following infection with microbial pathogens, nematodes, and symbionts (Felten et al. 2009; Grunewald et al. 2009a; Siemens et al. 2006; Wang et al. 2007). Quantification of GUS activity from the inoculated DR5:GUS plants showed that the inoculated roots had increased GUS activity compared with mockinoculated roots, suggesting that $F$. oxysporum infection had altered auxin homeostasis in the inoculated roots. Microscopic analysis showed that GUS activity was primarily located at the root tips of both Fusarium spp.-inoculated and uninoculated DR5:GUS plants (Fig. 3E and F). However, GUS staining was stronger in the inoculated roots and covered a larger root tip region than in mock-inoculated controls (Fig. 3E and F, indicated by black arrowheads). GUS staining of lateral root initials was also stronger and more visible in the inoculated plants compared with the mock-inoculated controls (Fig. 3F, indicated by red arrowheads). Also, in some inoculated plants, root regions other than root tips and lateral root initials displayed weak GUS staining (Fig. 3F, broken circles).

\section{Roles of Trp-derived auxin, IG, and camalexin on $F$. oxysporum resistance.}

To test the effect of endogenous auxin, IG, and Trp levels on disease development, we inoculated the cyp79b2 cyp79b3 double mutant as well as atr4/sur2, myb51/hig1, and atr2d mu- tants with $F$. oxysporum. As stated earlier, CYP79B2 and CYP79B3 play key roles in Trp-mediated auxin biosynthesis (Fig. 2) and the cyp79b2 cyp79b3 double mutant shows reduced auxin levels (Zhao et al. 2002). The SUPERROOT2 (SUR2) gene encodes CYP83B1, a cytochrome P450 enzyme that diverts IAOx, an intermediate in the auxin and IG pathway, toward IG (Fig. 2) (Barlier et al. 2000). The sur2 mutant shows significantly reduced IG but increased auxin levels in all organs (Barlier et al. 2000). MYB51 is a regulator of IG and IAA homeostasis and the activation-tagged myb51/hig 1 mutant shows increased IG levels whereas the loss-of-function mutant that we tested here shows reduced levels of IG (Gigolashvili et al. 2007). The atr $2 d$ mutant shows constitutive activation of Trp-pathway genes due to a dominant mutation in the $A L$ TERED TRYPTOPHAN REGULATION 2 (ATR2) gene (also known as $M Y C 3$ ) encoding a basic-helix-loop-helix transcription factor (Smolen et al. 2002). The closest homolog of ATR2 is MYC2, which regulates Trp-pathway genes during JA signaling (Dombrecht et al. 2007). In our inoculation experiments, none of these mutants showed any discernible effect on disease development (Fig. 4C to E). Next, we tested the disease phenotypes of 35S:ATRl plants and the atrld activation and atrl-2 loss-of-function mutants. ALTERED TRYPTOPHAN REGULATION 1 (ATR1) encodes MYB34, an activator of Trppathway genes, including $A S A 1, C Y P 79 B 2, C Y P 79 B 3$, and $C Y P 83 B 1 / S U R 2$, which were all inducible in both roots and leaves of $F$. oxysporum-inoculated plants. 35S:ATR1/MYB34 and the activation mutant atrld show increased levels of IG and free IAA (Celenza et al. 2005). The atr1-2 loss-of-function mutant shows reduced expression of IG biosynthesis genes CYP79B2, CYP79B3, and CYP83B1 and reduced levels of IG (Celenza et al. 2005). We also tested 35:ATR2 plants which, similar to the atr2d mutant, shows increased expression of Trp-pathway genes (Smolen et al. 2002). However, similarly to cyp79b2cyp79b3, atr4/sur2, myb51/hig1, and atr2d mutants, the 35S:ATR1/MYB34, atrld, atrl, and 35S:ATR2 plants did not show any altered resistance against $F$. oxysporum (Fig. $4 \mathrm{~F}$ to $J$ ), despite the fact that the genes encoding these proteins were mostly responsive to F. oxysporum (Fig. 2). It should be noted that we could not use the surl mutant which shows elevated auxin levels in our assessment, because this mutation also causes very severe developmental abnormalities and plant death (Boerjan et al. 1995).

The antimicrobial metabolite camalexin in Arabidopsis is also synthesized from indole-3-acetonitrile (IAN) through the Trp pathway (Bender and Celenza 2009) (Fig. 2). This raises the possibility that camalexin levels might also be altered in $F$. oxysporum-infected plants due to altered metabolic flux in the pathway. To test for a role of camalexin in defense against $F$. oxysporum, we inoculated the pad3 mutant but no altered disease phenotype was evident in the pad3 mutant (Fig. 4K). Taken together, these results suggest that endogenous auxin levels do not have a significant effect on the $F$. oxysporum disease development. In addition, based on the analyses of these relatively well-characterized mutants, one may conclude that IG and camalexin do not have any inhibitory effect on $F$. oxysporum disease development.

Exogenous auxin application is known to affect disease development against certain pathogens in Arabidopsis (Chen et al. 2007; Navarro et al. 2006). To test whether auxin has a role in modulating resistance against $F$. oxysporum, we treated the leaves of Arabidopsis plants with 20 or $100 \mu \mathrm{M}$ IAA 1 or 2 days prior to the inoculations of roots. In separate experiments, we dipped the roots in an inoculum that contained 20 or 100 $\mu \mathrm{M}$ IAA added just prior to inoculation. The disease development was then scored on these plants; however, none of the auxin treatments showed any significant effect on disease de- 
velopment (Fig. 4A and B; data not shown). There was no effect of similar treatments with synthetic auxins, 2,4-dichlorophenoxy acetic acid (2,4-D), and naphthalene acetic acid (NAA) on disease development (Supplementary Fig. S4A and B). Finally, we tested the effect of 6-fluoroindole (6-FI), a chemical inhibitor of the Trp-dependent IAA biosynthesis in Arabidopsis (Ludwig-Müller et al. 2010), on disease development. For this, we treated the leaves of wild-type plants with $10 \mu \mathrm{M}$ either 1 day before inoculations or added 6-FI directly to the inoculum used in plant inoculations. Neither of these treatments had a detectable effect on disease resistance. Together, these experiments indicate that the exogenous application of auxin or auxin biosynthesis inhibitors does not affect resistance to F. oxysporum in Arabidopsis.

Role of auxin signaling in $F$. oxysporum susceptibility.

Although the microarray experiments identified a number of genes involved in Trp-derived auxin biosynthesis as one of the functional groups of Fusarium-responsive genes, no differential expression from genes involved in auxin signaling was found in these analyses. We reasoned that this could be due to the time point of 2 days post inoculation used in the array experiments and that genes involved in signaling might be responsive to an earlier exchange of signals between host and

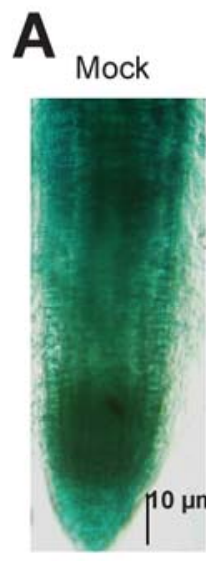

B

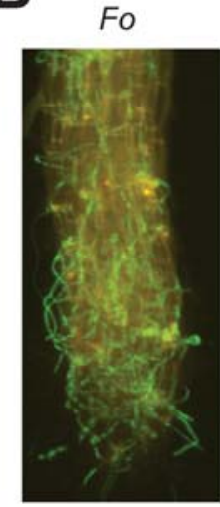

$\mathbf{E}$

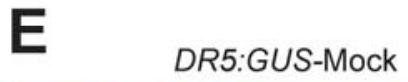

\section{C}
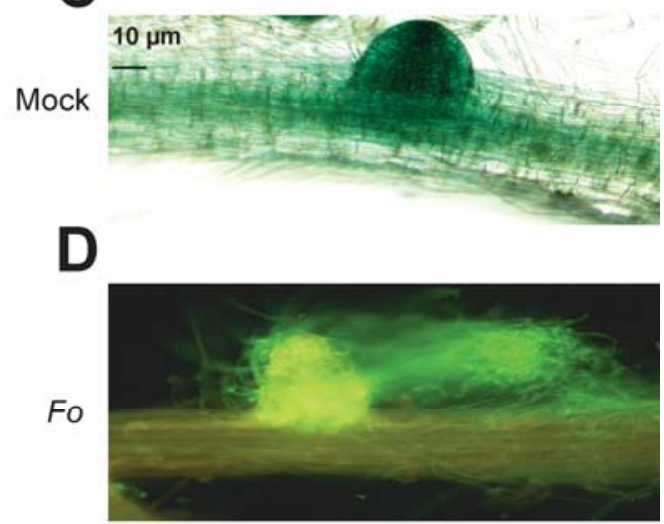

$\mathbf{F}$ DR5:GUS-F. oxysporum

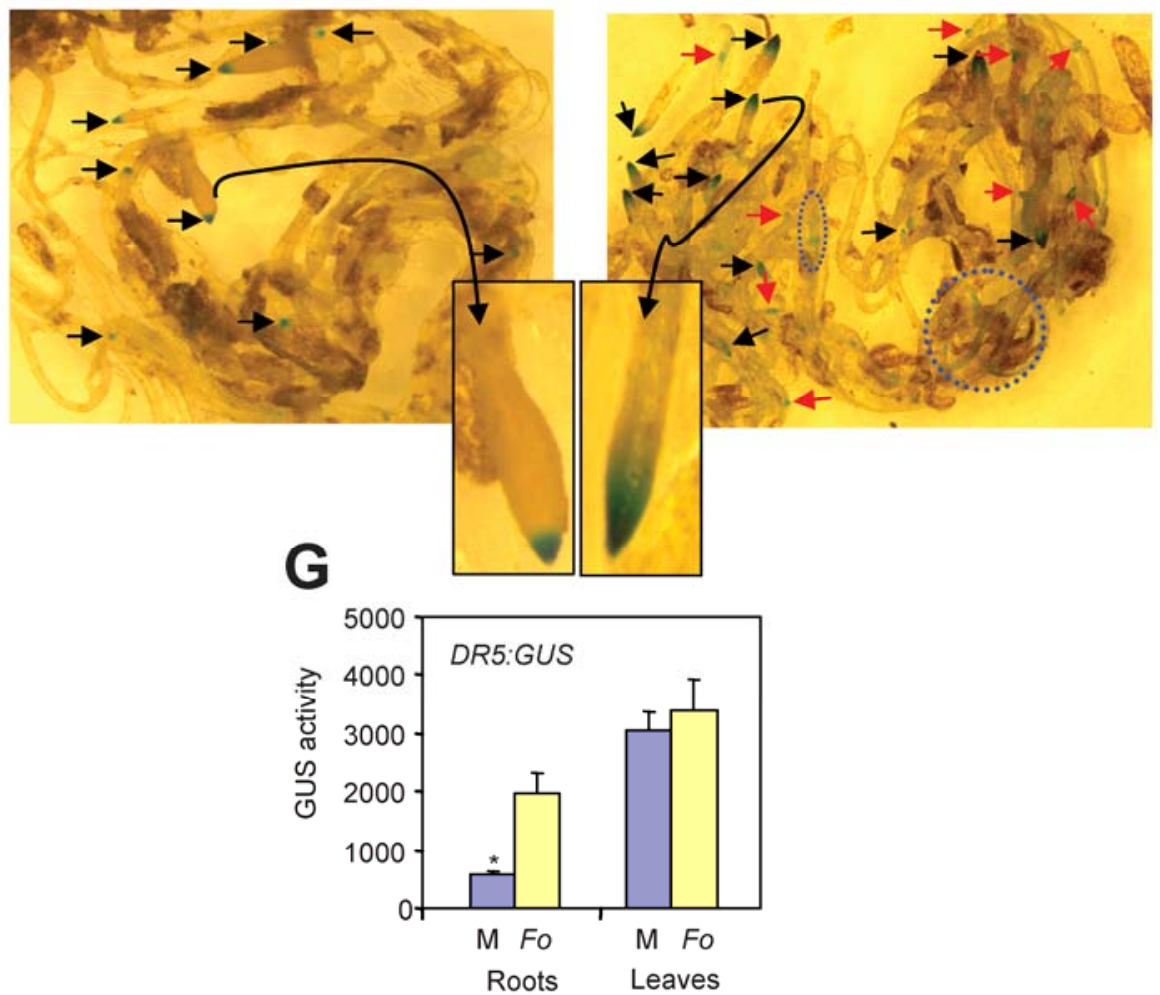

Fig. 3. Fusarium oxysporum initially colonizes root tips and lateral root initials in Arabidopsis. A and $\mathbf{C}$, Light microscopic view of the roots of uninoculated DR5:GUS seedlings stained for $\beta$-glucuronidase (GUS) activity. B and D, Roots of seedlings of similar age were also inoculated with a green fluorescent protein-expressing F. oxysporum strain and examined under a fluorescence microscope. $\mathbf{E}$ and $\mathbf{F}$, Roots of Arabidopsis plants expressing the DR5:GUS construct were either mock-inoculated or inoculated with F. oxysporum and analyzed 2 days after inoculations for the induction of GUS activity staining under a light microscope. Black arrowheads in $\mathrm{E}$ and $\mathrm{F}$ indicate root tips while red arrowheads in $\mathrm{F}$ indicate lateral root initials. Circles in $\mathrm{F}$ indicate root regions, other than tips and lateral root initials that show GUS staining. Insets: Enlarged view of two representative root tips from E, mock-treated and F, F. oxysporum inoculated plants. G, Fluorometric analysis of GUS activity in inoculated roots of DR5:GUS plants; * refers to a significant difference at $P<0.05$ between mock (M) and F. oxysporum treatment in the roots. 
pathogen. Therefore, we examined the expression of a number of known auxin-signaling genes in both roots and shoots of infected plants at the earlier time point of $3 \mathrm{~h}$ post inoculation. These experiments showed that a number of auxin-signaling genes, including TRANSPORT INHIBITOR RESPONSE1 (TIR1), AUXIN RESISTANT2 (AXR2), AUXIN RESISTANT3 (AXR3), AUXIN RESISTANT6 (AXR6), SUPPRESSOR OF G2 ALLELE OF SKPIB (SGT1B), and RING-BOXI (RBXI), were differentially expressed in at least one organ after $F$. oxysporum inoculation (Fig. 5A to G), suggesting that F. oxysporum infection may also modulate the auxin-signaling pathway.

To determine the possible effects of various auxin-signaling components on $F$. oxysporum resistance, we inoculated the relatively well-studied auxin-signaling mutants tirl, axrl, axr2, $a x r 3$, and $s g t 1 b$ with $F$. oxysporum. The TIRl gene encodes an auxin receptor while $A X R 2$ and $A X R 3$ encode the IAA/AUX proteins IAA7 and IAA17, respectively, which act as repressors of auxin-inducible gene expression (Mockaitis and Estelle 2008) while $S G T 1 B$ encodes a regulatory protein involved in $\mathrm{SCF}^{\mathrm{TIR}}$ mediated degradation of Aux/IAA proteins (Gray et al. 2003). Of the auxin-signaling mutants tested, axrl, axr2, axr3, and sgtlb showed increased $F$. oxysporum resistance, as evidenced by delayed symptom development relative to wild-type plants (Fig. 6A to $\mathrm{G}$ ) whereas no significant difference in disease resistance between tirl and wild-type plants was evident (Fig. 6H).
These experiments suggest that multiple components of auxin signaling, downstream of the auxin receptor, contribute to the susceptibility of Arabidopsis to F. oxysporum.

\section{A role for auxin transport in $\boldsymbol{F}$. oxysporum susceptibility.}

Auxin is synthesized in meristematic tissues, including shoot and root tips and lateral root initials, and transported within the plant either through phloem (known as non-polar auxin transport) or via one cell to another (known as polar auxin transport [PAT]). The inhibition of PAT through chemical or genetic means has been reported to result in the modulation of disease resistance to foliar fungal pathogens of Arabidopsis (Llorente et al. 2008).

Our gene expression analyses (Fig. 5G) showed that the gene called $B I G$ (also known as ASA1,CRM1,CAB1, DOC1, $L P R 1, T I R 3$, or $U M B 1$ ) was responsive to $F$. oxysporum. BIG encodes a calossin-like protein required for PAT (Gil et al. 2001 ) and we have previously reported a strong $F$. oxysporum resistance phenotype in this mutant (Kazan and Manners 2009). Here, we have undertaken further inoculation experiments to quantify the disease severity in this mutant and confirmed that the big mutant was indeed more resistant to $F$. oxysporum (Fig. 7A and B).

We decided to test the components of PAT to see whether they affect resistance to $F$. oxysporum. PAT is controlled by the
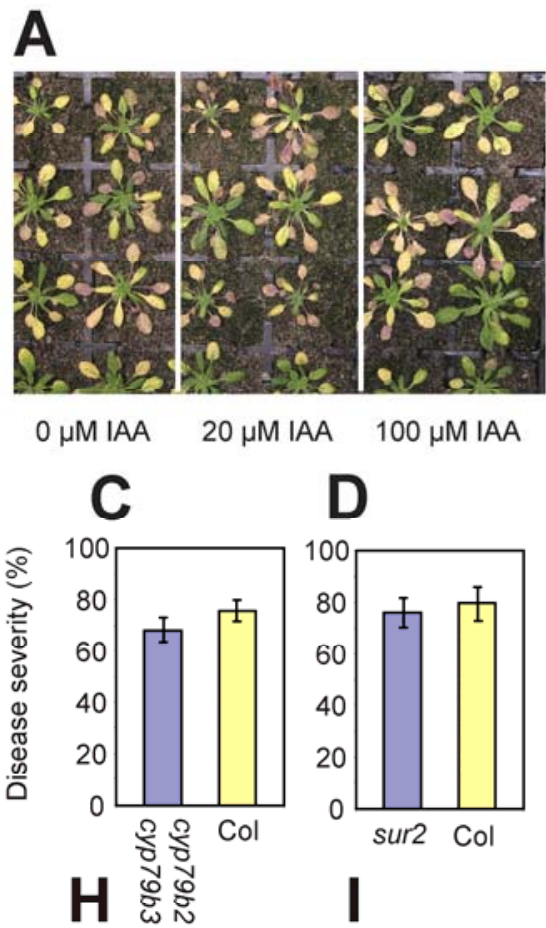

$100 \mu \mathrm{M}$ IAA
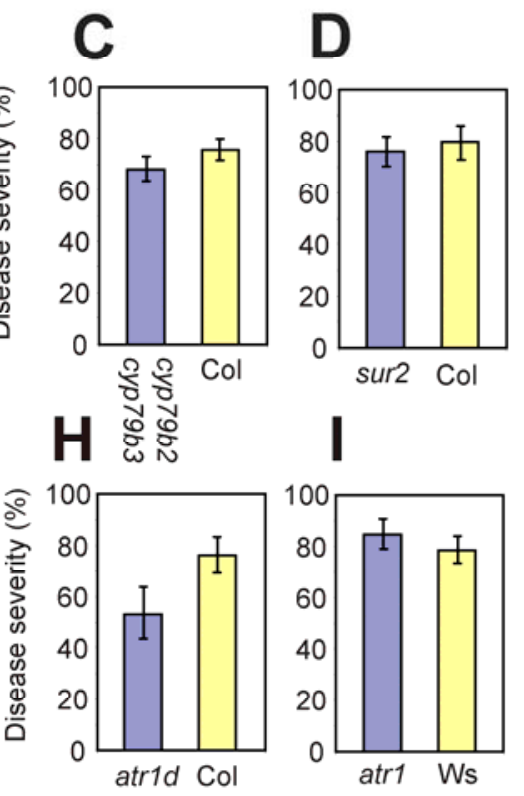

B

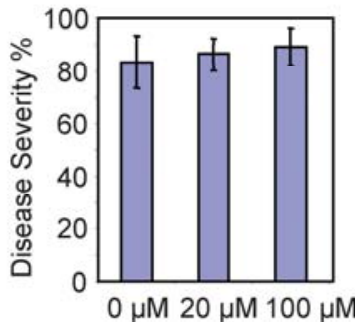

IAA
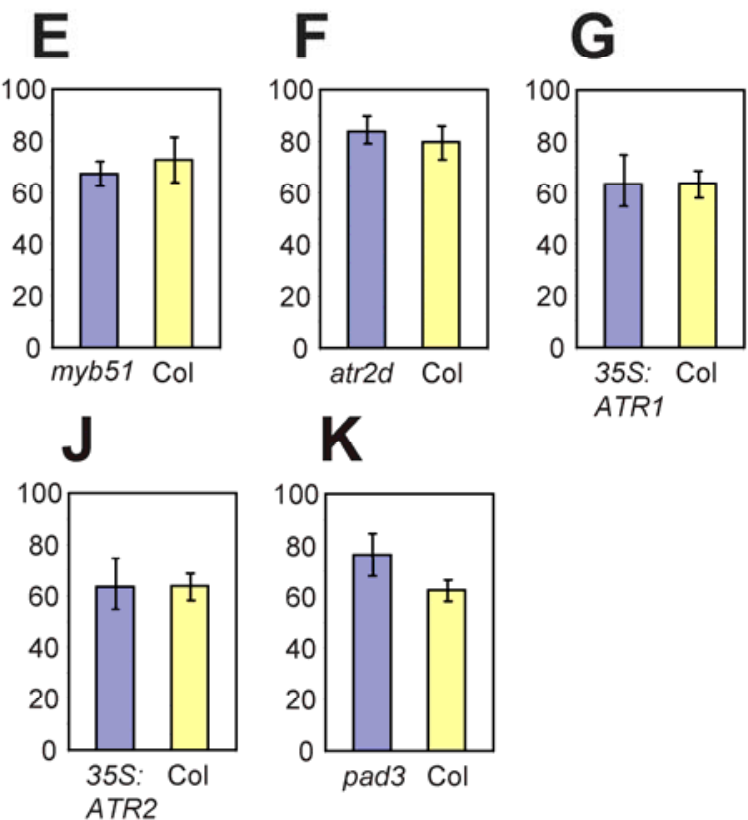

Fig. 4. Endogenous or exogenous 3-indolacetic acid (IAA) levels do not affect Fusarium oxysporum resistance. A and B, Arabidopsis plants were sprayed with two different IAA concentrations or mock-treated 1 day prior to inoculations with $F$. oxysporum and disease severity (percentage of plants showing disease symptoms) was measured 8 to 12 days after inoculations. $\mathbf{C}$ through $\mathbf{K}$, Arabidopsis mutants cyp79b2 cyp79b3, sur2, myb51/hig1, atr2d, atrld, atr1, and pad 3 and transgenic plants expressing 35S:ATR1/MYB34 or 35S:ATR2 constructs were inoculated with F. oxysporum and disease severity was assessed 8 to 10 days after inoculations. Average data from three independent inoculation experiments with standard error are shown. 
localization of auxin influx and efflux carriers to the plasma membrane (Titapiwatanakun and Murphy 2009). AUXIN RESISTANT1 (AUX1) controls auxin influx and its localization is regulated by AUXIN RESISTANT4 (AXR4) (Bennett et al. 1996; Dharmasiri et al. 2006; Swarup et al. 2001). We found the auxl and axr4 mutants to have significantly increased resistance to F. oxysporum (Fig. 7C and D). Auxin efflux is regulated by the pin-formed (PIN) proteins together with the multidrug resistance/phosphoglycoprotein (MDR/PGP) ATPbinding cassette transporters (Titapiwatanakun and Murphy
A
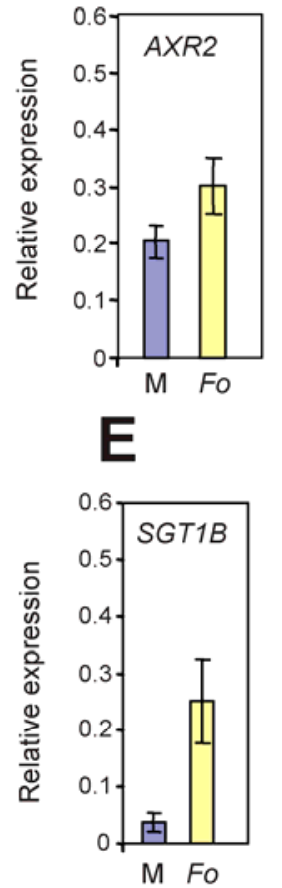
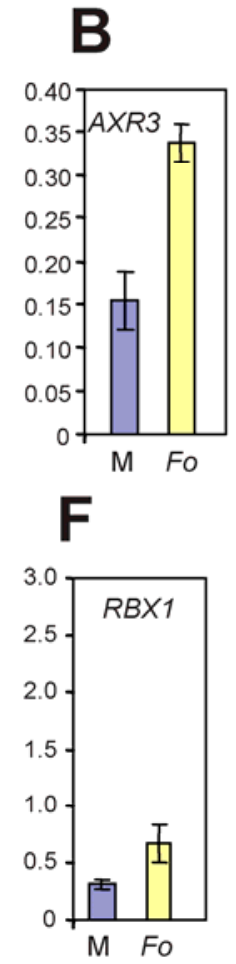
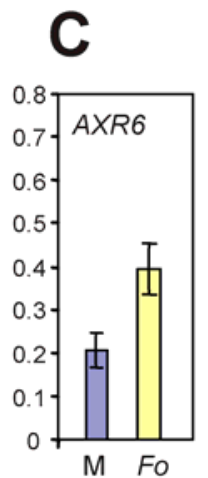

G

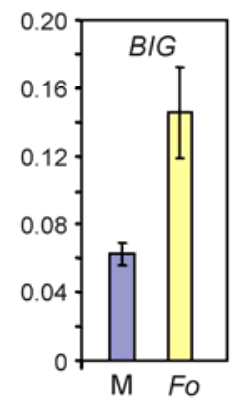

D

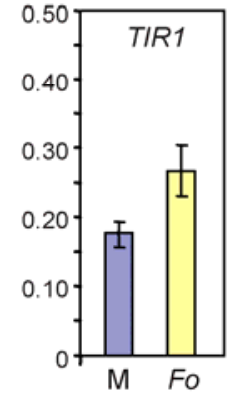

Fig. 5. A through G, Fusarium oxysporum induces auxin signaling genes in Arabidopsis. Data are average of three independent inoculation experiments ( $3 \mathrm{~h}$ time point) with standard error. $\mathrm{M}=$ Mock; $F o=F$. oxysporum.

A

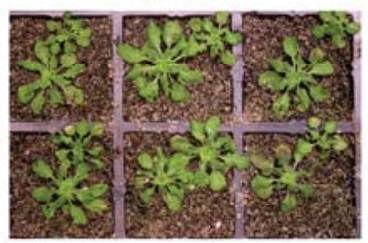

C

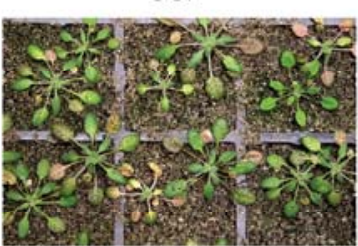

D

axr3 Col
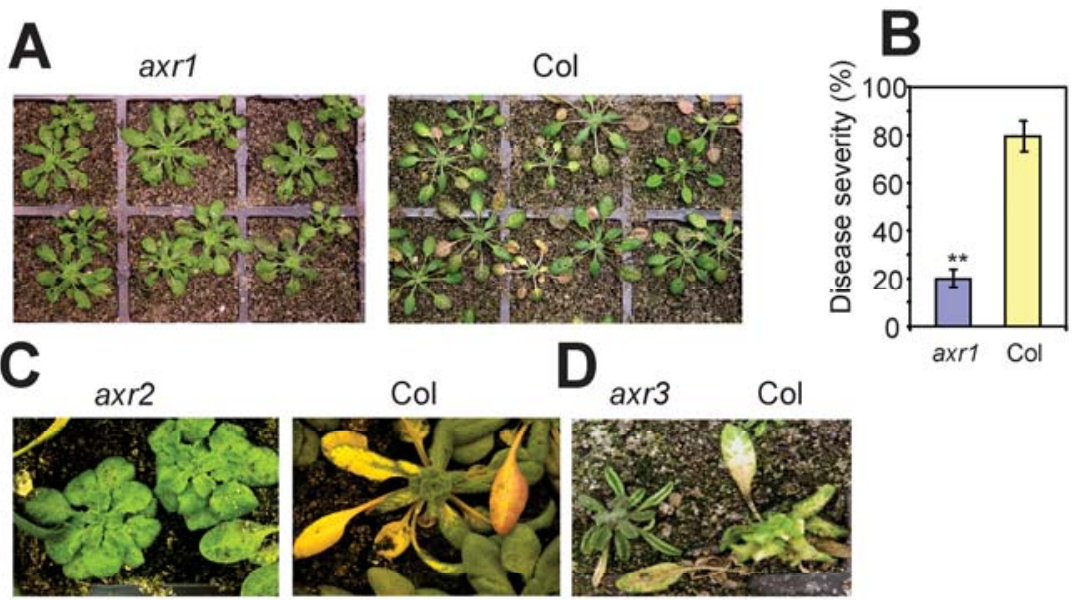

E

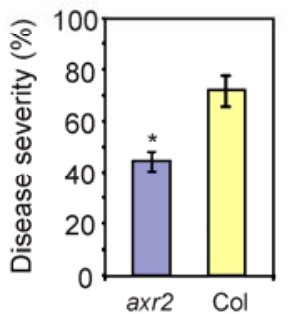

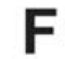

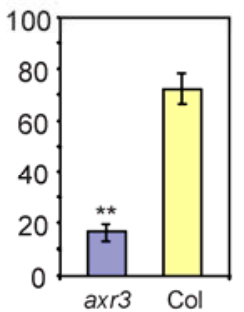

G

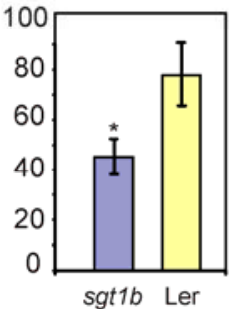

H

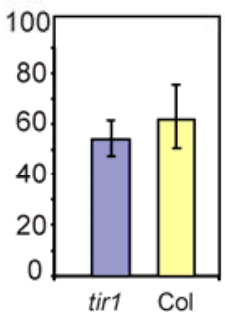

Fig. 6. Arabidopsis auxin signaling mutants show increased resistance to Fusarium oxysporum. Mutants and their respective wild-type (Col or Ler) plants were inoculated with $F$. oxysporum and disease severity was accessed 8 days after inoculations. Average data from three independent inoculation experiments with standard error are shown in $\mathrm{B}$ and $\mathrm{E}$ through $\mathrm{H} ; *$ and ** refer to significant differences at $P<0.05$ and 0.01 , respectively. 
2009). We tested the disease phenotypes of $m d r l / p g p l$ (Lin and Wang 2005; Noh et al. 2001), pin2/eirl (Roman et al. 1995), and the pin3 (Friml et al. 2002) mutant that are all compromised in auxin transport. However, in our inoculation experiments. only pin2/eirl showed a significantly different disease phenotype (Fig. 7E to G), possibly due to the redundancy of auxin efflux facilitators or transporters involved in PAT (Friml et al. 2002; Titapiwatanakun and Murphy 2009).

As reported earlier, the expression of genes involved in flavonoid biosynthesis was increased in $F$. oxysporum-inoculated plants. Flavonoids (anthocyanins) are known to be the endogenous inhibitors of PAT and this has historically been studied in the Arabidopsis tt4 mutant, which is deficient in flavonoids due to a mutation in the CHALCONE SYNTHASE (CHS) gene. This mutant shows increased auxin transport rates (Peer and Murphy 2007) and our inoculation experiments showed that the $t t 4$ mutant was more susceptible to $F$. oxysporum than wild-type plants (Fig. 7H), further suggesting an association between PAT and susceptibility to $F$. oxysporum.

To further test whether PAT plays a role in promoting susceptibility to $F$. oxysporum, we treated Arabidopsis plants with 2,3,5-triio-dobenzoic acid (TIBA), a chemical inhibitor of PAT, prior to inoculation of roots with $F$. oxysporum. TIBA-treated plants were then inoculated and scored for disease development. These experiments showed that TIBA treatment significantly reduced disease development, providing additional support to the view that PAT promotes susceptibility to F. oxysporum (Fig. 7I and $\mathrm{J}$ ). We also tested the effect of TIBA treatment of roots during inoculation on disease development by this pathogen. However, we found that TIBA, when added directly to the inoculum, had inhibitory effects on spore germination and, therefore, its effect on disease development could not be reliably tested when it is applied to the roots (data not shown). Finally, plants treated with 1-naphthylphthalamic acid (NPA), another chemical inhibitor of PAT, also showed increased resistance to F. oxysporum.

\section{F. oxysporum resistance in auxin-signaling mutants is independent of salicylate-regulated defense.}

As shown in this article, $F$. oxysporum infection downregulates SA-responsive $P R$ gene expression, in parallel with the upregulation of JA- and auxin-responsive genes (Figs. 1 and 2 ). This is consistent with the antagonistic cross-talk reported between the SA and JA pathways as well as the SA and auxin pathways (Bari and Jones 2009; Kazan and Manners 2008, 2009; Lorenzo and Solano 2005). Therefore, we speculated that the increased $F$. oxysporum resistance observed in auxin-

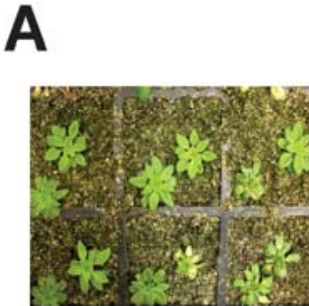

big

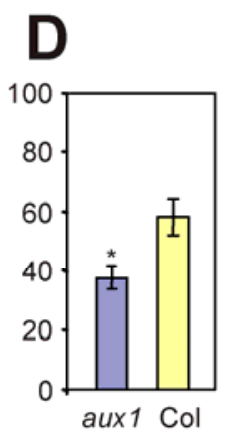

I

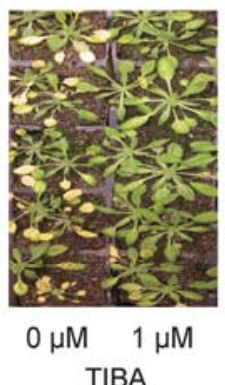

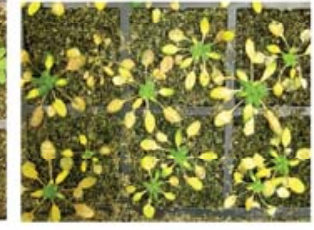

Col
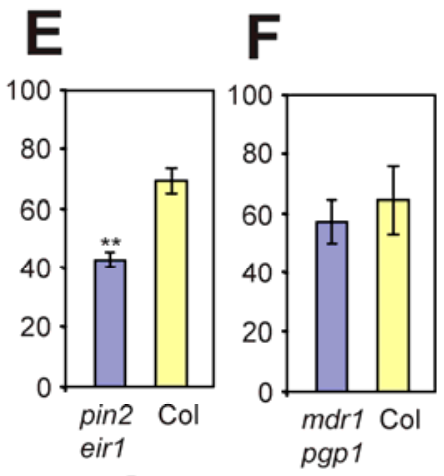

J

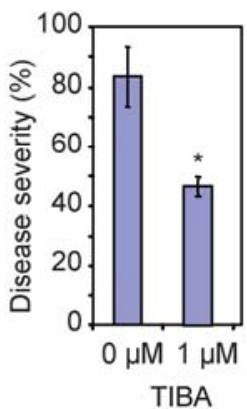

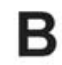
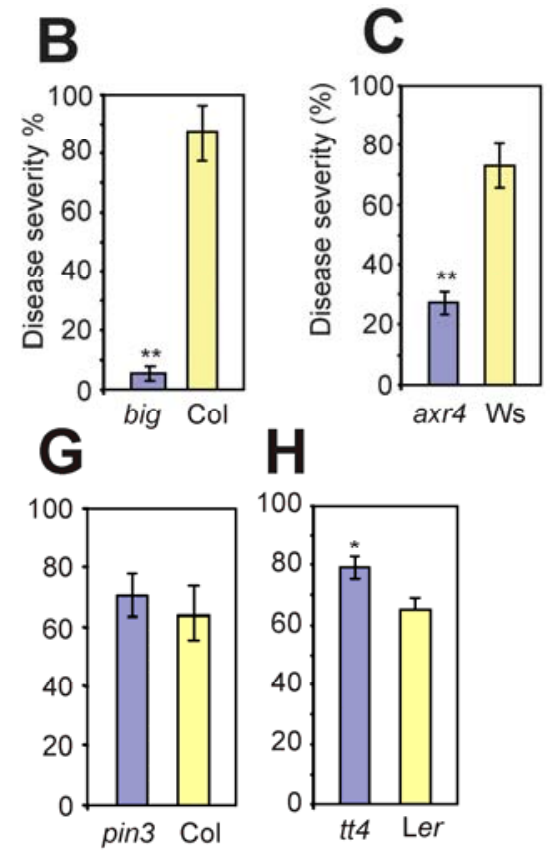

Fig. 7. Genetic and chemical alterations of polar auxin transport leads to Fusarium oxysporum resistance. A, Representative disease pheontypes of the big mutant and wild-type plants. B through H, Arabidopsis mutants big, axr4, aux1, pin2/eir, mdr1/pgp1, pin3, tt4, and their respective wild-type plants were inoculated with $F$. oxysporum as described previously and disease severity was scored 8 to 10 days after inoculation. I and $\mathbf{J}$, Wild-type Arabidopsis plants were either mock treated or treated with $1 \mu \mathrm{M}$ auxin transport inhibitor 2,3,5-triio-dobenzoic acid (TIBA) 1 day prior to inoculations and disease severity was scored 8 days after inoculations; * and ** refer to significant differences at $P<0.05$ and 0.01 , respectively. 
signaling mutants may be due to an activated expression of SA-responsive defense genes, which are known to have some effect against $F$. oxysporum in Arabidopsis (Diener and Ausubel, 2005; Edgar et al. 2006). To test this possibility, we have analyzed the expression of SA-responsive defense genes PR1, PR2 ( $\beta$-1,3-GLUCANASE [BGL2]), and PR5 in F. oxysporum-inoculated mutants impaired in auxin-signaling and wild-type plants. F. oxysporum infection of both the $s g t 1 b$ mutant and wild-type plants led to a similar downregulation of the expression of SA-responsive $P R$ genes (Supplementary Fig. S5A to C), suggesting that increased SA-dependent defenses were not responsible for the observed increase in $F$. oxysporum resistance in this auxin-signaling mutant.

To further test the importance of SA in potentially conferring increased disease resistance in auxin-signaling mutants, we constructed axrl/NahG and axr3/NahG plants by crossing axrl and axr3 plants with a $35 S: N a h G$ plant that constitutively expresses the SA-degrading enzyme salicylate hydroxylase. Comparative examination of the disease resistance phenotypes of homozygous axrl/NahG and axr3/NahG plants with axrl and axr 3 mutants, respectively, did not show any difference in disease resistance, further suggesting that increased $F$. oxysporum resistance observed in the axrl and axr3 mutants was not due to elevated SA levels or signaling.

\section{DISCUSSION}

F. oxysporum is an important fungal pathogen of many plant species. Pathogenic strains are hemibiotrophs and have a complex, multistage infection process. The infection begins with an initial, seemingly biotrophic phase of root colonization and subsequent invasion of the shoot via the xylem. The invasion into the shoot is then followed by a necrotrophic phase involving host wilting, senescence, and, ultimately, leaf necrosis. We have previously shown that the fungus manipulates the host's own JA-dependent signaling pathways to affect the latter stages of senescence and necrosis in the disease process (Thatcher et al. 2009) and, in this article, we present evidence that the full development of Fusarium wilt disease also requires components of the host's auxin-signaling and transport pathways. Together, a picture is emerging where the pathogen exploits multiple host-signaling components to promote disease development. The transcriptional activation of genes involved in JA and auxin signaling in the leaves (systemic tissue) of $F$. oxysporum-inoculated plants further suggests that the pathogen activates an "induced systemic susceptibility" program to colonize and eventually kill the host plant. It is likely that specific effectors or toxins produced by $F$. oxysporum play a role in fungal pathogenesis. Previous research showed that the fungal culture filtrate has the ability to cause chlorosis when applied to Arabidopsis leaves (Thatcher et al. 2009). However, further research is required to understand the molecular mechanisms of fungal pathogenicity.

The global analysis of host gene expression undertaken here during the infection process clearly demonstrated that $F$. oxysporum invokes a coordinated response from the host that involves the activation of JA-dependent defense genes, Trp metabolism, and alterations of other defense-related gene families such as LTP. Further functional analysis using mutants for key genes of some of the induced processes such as the production of Trp-derived glucosinolates and indole phytoalexins suggested that these responses are probably ineffective in constraining $F$. oxysporum when it infects via the roots. Furthermore, although genes involved in auxin biosynthesis were induced, functional analysis showed that these responses also appeared not to be directly involved in disease development. Exogenous application of auxin to the leaves or roots also had no effect on disease de- velopment. In contrast, mutants with impaired auxin transport and signaling showed enhanced resistance, indicating that changes in the distribution of auxin at the root tip regions may be more important for disease susceptibility than overall changes in auxin levels. Indeed, the auxin-signaling and transport mutants that displayed increased resistance to $F$. oxysporum are all known to have altered root auxin distributions as well as reduced lateral root development (Péret et al. 2009). The fungus may harness auxin transport and signaling to either evade detection by the host, suppress host defenses, or enhance host processes that are advantageous to fungal colonization and disease development. These aspects of auxin function in Fusarium wilt disease are discussed in more detail below.

\section{F. oxysporum alters local and systemic expression of genes involved in JA and Trp pathways.}

Our analyses of the Arabidopsis transcriptome responding to $F$. oxysporum infection revealed that the pathogen primarily activated genes involved in JA biosynthesis, signaling, and defense. Interestingly, the $F$. oxysporum-induced genes from the other functional groups, such as the genes involved in Trp-mediated auxin and IG biosynthesis, are also mostly JA inducible (Dombrecht et al. 2007; Sun et al. 2009; Zimmermann et al. 2004). Our analysis of the microarray data showed a strong JA responsiveness for $F$. oxysporum-responsive genes. Approximately $96 \%$ of the genes induced by $F$. oxysporum greater than 1.5-fold were JA inducible and, likewise, $95 \%$ of the genes repressed by $F$. oxysporum greater than 1.5 -fold were repressed by JA. The $F$. oxysporum-induced genes we identified here show a significant overlap with the JA-responsive genes that were found to be upregulated in plants overexpressing ERF1 and ORA59 (Lorenzo et al. 2003; Pré et al. 2008). ERF1 and ORA59 have been shown to activate the expression of JA defense genes as well as Trp biosynthetic genes (Lorenzo et al. 2003; Pré et al. 2008) and, indeed, we found the expression of ORA59 to be induced by F. oxysporum; however, the expression of ERF1 was not (Fig. 2). In addition, we found upregulation of $E R F 2$, which has also been shown to activate JA defense genes, as well as upregulation of AtERF1, the closest relative to ERF2 (Brown et al. 2003; McGrath et al. 2005).

We also found increased expression of $M Y C 2$ by $F$. oxysporum (Fig. 2). MYC2 is a negative regulator of JA-associated defense genes and the Trp biosynthetic pathway (Dombrecht et al. 2007; Lorenzo et al. 2004) and is required for $F$. oxysporum susceptibility (Anderson et al. 2004). Although the upregulation of both positive and negative regulators of JA signaling by $F$. $o x$ ysporum appears to be paradoxical, it has been well established that negative regulators of plant hormone-signaling pathways are induced to prevent overactivation of the hormone pathway. This has been demonstrated previously with the JAZ repressor proteins being induced rapidly after JA treatment (Chini et al. 2007; Thines et al. 2007). We also observed the upregulation of JAZ2 and JAZ9 expression by $F$. oxysporum infection (Fig. 2). However, despite the activation of JA repressors proteins, an overall increase in JA-associated gene expression was observed. Overall, these results suggest that $F$. oxysporum infection alters the plant transcriptome largely through its effect on the JA-signaling pathway.

\section{Effects of IG and camalexin on $F$. oxysporum disease development.}

Interestingly, despite strong induction of genes involved in IG biosynthesis, the Arabidopsis mutants with altered IG biosynthesis did not have any significant effect on disease development, suggesting that IG are probably not a constraint on $F$. oxysporum infection and disease development. Similarly to the infection by F. oxysporum, infection of Arabidopsis roots by the obligate 
biotroph $P$. brassicae, that causes clubroot disease, also induces Trp-mediated auxin and IG genes (Ludwig-Müller 2009; Ludwig-Müller and Schuller 2008; Ludwig-Müller et al. 2009; Siemens et al. 2006). However, similarly to our results, the IG pathway was found not to affect clubroot symptom development (Siemens et al. 2008). In contrast, the importance of the IG pathway in Arabidopsis against leaf-infecting pathogens has been recently demonstrated (Bednarek et al. 2009; Clay et al. 2009; Consonni et al. 2010; Sanchez-Vallet et al. 2010; Schlaeppi et al. 2010). It is possible that the biotrophic stages of root infection used by these pathogens enable them to escape contact with IG that are predominant in roots (van Dam et al. 2009). For example, $F$. oxysporum mainly colonizes roots via xylem vessels and $P$. brassicae colonizes the root cortex via plasmodia that form isolated intracellular compartments in the plant cell. It is possible that these root pathogens have evolved strategies to either resist or evade root defenses such as IG to become pathogenic on Brassicaceae family members.

\section{Auxin transport promotes susceptibility to $F$. oxysporum in Arabidopsis.}

Using the DR5:GUS reporter, we observed a threefold increase in GUS activity in infected roots, indicating that $F$. oxysporum infection alters root auxin homeostasis, especially in the regions such as root tips and lateral root initials. DR5:GUS activity has been strongly correlated with direct IAA measurement in the root tissue (Normanly 2010). Similarly to our results, a fivefold increase in free IAA levels of the $F$. oxysporum-infected roots of cotton was reported (Dowd et al. 2004). Despite this, we found that pathogen inoculations of mutant or transgenic Arabidopsis plants with increased (e.g., 35S:ATR1/MYB34) or reduced (e.g., cyp79b2cyp79b3) endogenous auxin levels did not alter disease development. Similar to our results which showed no detectable increase in DR5:GUS activity in the leaves of $F$. oxysporum-infected plants; no increase in IAA levels was found in the leaves of plant undergoing systemic acquired resistance (SAR) triggered by Pseudomonas syringae, despite upregulation of genes involved Trp-mediated auxin biosynthesis (Truman et al. 2010).

Although the mutation or overexpression of IAA biosynthetic genes did not appear to affect disease development, our results showed that certain PAT components are required for pathogen susceptibility. This could be due to the fact that auxin synthesized locally in roots is a relatively small proportion compared with the amount of auxin transported to the roots from aerial parts. Therefore, the pathogen may be targeting PAT components as opposed to the biosynthetic pathway as a more effective way of modulating auxin levels in specific cell types of the root to cause disease. Indeed, we found that $\operatorname{axr} 4$, aux 1, pin2/eirl, and big/doc were more resistant to F. oxysporum (Fig. 7). The auxl mutant has recently been shown to be compromised in SAR response, which was at least partly mediated by JA in Arabidopsis (Trumann et al. 2010). Moreover, mutations in auxin transport genes $A U X 1, P I N 2$, and $B I G$ reduce plant biomass production in response to infection of roots by Trichoderma virens, a beneficial root-infecting fungus (ContrerasCornejo et al. 2009). Also, the pin2/eirl mutants were found to be compromised in induced systemic resistance induced by the root-infecting nonpathogenic bacteria $P$. fluorescens (Iavicoli et al. 2003; Knoester et al. 1999) and in lateral root formation after infection by the ectomycorrhizal fungus Laccaria bicolour (Felten et al. 2009). The proposition that PAT promotes susceptibility to $F$. oxysporum is further supported by the demonstration that the chemical inhibition of PAT by TIBA also reduced disease development. Furthermore, the $t t 4$ mutant showed increased susceptibility, and it is known that PAT is more active in $t t 4$ because of a deficiency in flavonoids which are endogenous inhibitors of PAT (Peer and Murphy 2007). Of particular interest, it has recently been proposed that flavonoids act as negative regulators of PIN2 (Santelia et al. 2008). Our results, which showed increased and reduced resistance in pin2/eirl and $t t 4$, respectively, are in line with a role of auxin transport processes in providing susceptibility to $F$. oxysporum.

Interestingly, PAT appears to differentially regulate resistance to different pathogens in Arabidopsis. Previous research showed that TIBA treatment caused increased susceptibility to the leaf necrotroph Plectosphaerella cucumerina (Llorente et al. 2008) whereas we observed increased $F$. oxysporum resistance in TIBA-treated plants. The different effects of auxin transport inhibitors on different pathogens could be explained based on their differential effects on JA- and SA-signaling pathways, which are often required for resistance to necrotrophic and biotrophic pathogens, respectively. TIBA treatment activates SA signaling (Llorente et al. 2008) that is known to promote resistance to $F$. oxysporum (Diener and Ausubel 2005; Edgar et al. 2006). However, TIBA also suppresses JA signaling (Llorente et al. 2008), which is known to promote resistance to necrotrophs such as $P$. cucumerina but also susceptibility to $F$. oxysporum. These observations further emphasize the frequently opposing roles that plant hormone pathways have on disease development by different pathogens.

\section{Auxin signaling promotes susceptibility to $F$. oxysporum.}

In addition to PAT components, emerging evidence indicates that auxin-signaling genes also regulate resistance to different plant pathogens (Kazan and Manners 2009). For instance, auxin signaling is required for resistance to necrotrophic pathogens such as Botrytis cinerea and P. cucumerina (Llorente et al. 2008) and susceptibility to the bacterial pathogen Pseudomonas syringae and the biotrophic oomycete pathogen Hyaloperonospora parasitica (Wang et al. 2007). Furthermore, SA-mediated inhibition of $P$. syringae growth in Arabidopsis requires the suppression of auxin signaling (Wang et al. 2007). More recently, several auxin-signaling mutants were shown to be defective in the establishment of systemic immunity following challenge with avirulent $P$. syringae (Truman et al. 2010).

Our results from auxin-signaling mutants axrl, axr2, and axr3 showed increased resistance to $F$. oxysporum. The axrl and axr 2 mutants were previously found to be more susceptible to the necrotrophic leaf-infecting pathogen Plectosphaerella cucumerina (Llorente et al. 2008). The sgtlb mutant that showed increased resistance to $F$. oxysporum in our experiments was also more resistant to the necrotrophic fungal pathogen F. culmorum (Cuzick et al. 2009) as well as coronatinemediated lesion development by Pseudomonas syringae pv. tomato (Uppalapati et al. 2011). However, sgtlb shows increased susceptibility to biotrophic pathogens such as the leaf-infecting downy mildew pathogen $H$. parasitica (Tör et al. 2002). In contrast to these mutants, the auxin receptor mutant tirl did not show any altered resistance to $F$. oxysporum. Similarly, the tirl mutant does not show any altered resistance to necrotrophic fungal pathogens B. cinerea and Plectosphaerella cucumerina (Llorente et al. 2008). These results may be explained by the redundancy of auxin receptors (Chapman and Estelle 2009). Collectively, these findings demonstrate the importance of auxin signaling in determining disease outcomes to a variety of bacterial and fungal plant pathogens that possess differing infection strategies and infect either leaves or roots.

\section{Possible mechanisms of auxin-signaling- and transport-mediated susceptibility to $F$. oxysporum?}

Although some auxin-signaling mutants showed increased quantitative resistance to $F$. oxysporum, no significant alterations in defense gene expression signatures of these mutants 
during infection could be found in this study. Furthermore, our results also indicated that the disease resistance phenotypes of auxin-signaling mutants were not SA dependent because disease phenotypes of at least two auxin-signaling mutants remained unchanged when endogenous SA was depleted by transgenic expression of the SA-degrading enzyme salicylate hydroxylase in these mutants. Together, these results suggest that the $F$. oxysporum resistance observed in auxin mutants was not dependent on increased defense gene expression. Similarly, the pathogen-responsive expression of $P R 1$ and $P D F 1.2$ in auxin-signaling mutants axrl and $a x r 2$ after inoculation with $P$. cucumerina remains unchanged, despite the increased resistance of these mutants to this pathogen (Llorente et al. 2008).

In auxin signaling, ubiquitin-mediated degradation of AUX and IAA proteins acting as negative regulators is critical for the activation of auxin responses. Of the mutants employed here, the degradation of AUX and IAA proteins is compromised in the axrl mutant because the AXR1 protein is required for posttranslation modification of CUL1, a component of the SCF complex involved in the degradation of AUX and IAA proteins (Chapman and Estelle 2009). Also, the axr2/iaa7 and axr3/ iaal7 mutants contain gain-of-function mutations in $A X R 2$ and $A X R 3$ that make the AUX and IAA proteins IAA7 and IAA17 resistant to degradation (Chapman and Estelle 2009). Similarly, SGT1B is required for $\mathrm{SCF}^{-{ }^{T R} 1}$-mediated protein degradation and the $s g t l b$ mutant is compromised in protein ubiquitination (Gray et al. 2003). Ubiquitination is also required in auxin transport. A recent study showed that PIN2/EIR2, which promoted susceptibility to $F$. oxysporum in this study, is ubiquitinated during root gravitrophism (Abas et al. 2006).

The increased disease susceptibility observed in auxin-signaling mutants such as axrl and axr2 against leaf-infecting necrotrophic fungal pathogens has also previously been explained by the effects of compromised protein ubiquitination pathways (Llorente et al. 2008). The treatment of wild-type plants with a proteasome inhibitor increased susceptibility to leaf-infecting necrotrophs whereas this treatment did not have any further effect on the susceptibility phenotypes of axrl and axr2 (Llorente et al. 2008). Therefore, it appears that increased $F$. oxysporum resistance observed in all these mutants is associated with a compromised protein ubiquitination.

Indeed, we have previously shown that the F-box protein COI1, the JA receptor involved in JA- and SCF-mediated degradation of JAZ repressors, acts as an $F$. oxysporum susceptibility gene because coil loss-of-function mutants show strong $F$. oxysporum resistance (Thatcher et al. 2009). This role for COI1 implies that protein degradation is required for $F$. oxysporum susceptibility and interfering with this process would increase resistance. The components of the SCF complex are required for both JA and auxin signaling (Ren et al. 2005; Uppalapati et al. 2011); therefore, determining whether the increased resistance we see in these mutants is due to a disruption in auxin signaling or JA signaling is difficult because both pathways are affected by a compromised SCF complex.

However, the $A X R 2$ and $A X R 3$ genes have not yet been shown to have a role in JA signaling and, because mutation of these genes also affected resistance, this suggests a role for auxin-mediated susceptibility that is distinct from JA signaling. The increasing number of reports (Kazan and Manners 2009) demonstrating a link between auxin-signaling components and disease resistance suggests a strong role for auxin in modulating the defense response.

In conclusion, it is now well established that many soil-living organisms ranging from symbiotic bacteria (e.g., Rhizobium spp.) to pathogenic fungi as well as parasitic plants (e.g., Orobanche spp.) and nematodes can directly or indi- rectly alter the host plant's auxin biosynthesis, signaling, and transport during their interactions with plant roots (Bar-Nun et al. 2008; Grunewald et al. 2009b). Interrupting host auxin transport reduces nodulation in legumes (Grunewald et al. 2009 b) and the ability of endophytic organisms to interact with plant roots and promote growth. Our study also suggested that various components of the host's auxin signaling and transport are needed for $F$. oxysporum to exert full pathogenicity on Arabidopsis. Similarly, in the absence of an intact auxin signaling and transport, plant-pathogenic and parasitic soil organisms such as nematodes and parasitic plants have a reduced ability to cause damage (Contreras-Cornejo et al. 2009; Felten et al. 2009; Grunewald et al. 2009a and b; Lee et al. 2011; this study). This further suggests that soil microorganisms, regardless of their pathogenicity status, have developed strategies to exploit auxin signaling and transport to be able to interact with plant roots. Further delineation of the molecular mechanism behind this manipulation may reveal a common gateway into plant roots and, potentially, a solution to keeping the gateway closed.

\section{MATERIALS AND METHODS}

\section{Plant material.}

The following mutants obtained from the Arabidopsis Biological Resource Centre were used in inoculation experiments: axr1 (CS3075), axr2 (CS3077), axr3 (CS57504), axr4 (CS8018), big/tir3 (CS3928), atr4/sur2 (SALK_028573), pad3 (CS3805), tirl (CS3798), pgp1/mdrl (SALK_83649), myb51/hig1 (SALK_059765; SALK_059771), auxl (CS3074), pin2/eirl (CS8058), and pin3 (CS9364). The sgtlb mutant seed were provided by J. Parker; atr2d, 35S:ATR1/MYB34, atrld, atr1-2, and 35S:ATR2 seed by J. Bender; DR5:GUS seed by T. Guilfoyle; pad3 seed by B. Thomma; cyp79b2cyp79b3 by J. Celenza and H. Kasahara (Sugawara et al. 2009); and 35:NahG seed by Syngenta. To generate axrl/NahG and axr3/NahG plants, crosses were made between axrl and 35S:NahG and axr3 and 35S:NahG plants, where axrl and axr3 plants were used as the female parent. The $\mathrm{F}_{1}$ plants were self pollinated. DNA was isolated from individual $\mathrm{F}_{2}$ plants with typical mutant phenotypes with $F$. oxysporum, and the presence of the $35 S: N a h G$ transgene was identified before inoculations by PCR as described previously (Thatcher et al. 2009). Plants with mutant phenotypes but without the 35S:NahG transgene were used as controls in inoculation experiments.

\section{RT-Q-PCR analysis.}

The sequences of the primer sequences used in RT-Q-PCR experiments were given previously for most genes (Dombrecht et al. 2007; Kidd et al. 2009; McGrath et al. 2005; Thatcher et al. 2009) and also supplied in Supplementary Table S2. Quantitative RT-PCR experiments were done as described previously (McGrath et al. 2005). Briefly, for all data analysis, amplification plots were analyzed using a cycle threshold $(\mathrm{Ct})$ value of 0.2 across all experiments. In addition, the PCR primer efficiency ( $E$ value) of each primer pair in each reaction was calculated using LinReg PCR software (Ramakers et al. 2003) from the $\Delta \mathrm{Rn}$ values obtained from the SDS 2.3 software (Applied Biosystems). Absolute gene expression levels relative to the previously validated reference genes $\beta$ ACTIN2, $\beta$-ACTIN7, and $\beta$-ACTIN8 were used for each cDNA sample using the equation relative abundance $=\left(\right.$ Egene $^{\wedge}(-\mathrm{Ct}$ gene $)) /\left(\mathrm{E} A C T I N^{\wedge}(-\mathrm{Ct} A C T I N)\right)$. Three biological replicates of mock and treated samples were used, and the average ratio of these values was used to determine the fold change in transcript level in treatment samples compared with control. 


\section{Microarray analysis.}

Microarray analyses have been previously described (Kidd et al. 2009). Briefly, four independent biological replicates (20 plants each) of Col-0 plants were root dipped in either water or an $F$. oxysporum spore suspension of $10^{6}$ spores $/ \mathrm{ml}$ in water and replanted in soil. The leaf material was collected 2 days after inoculation and total RNA extracted using the RNeasy plant mini kit (Qiagen, Hilden, Germany). The labeling, hybridization, washing, and scanning steps onto 16 ATH1 GeneChip arrays were done by the Australian Genome Research Facility (Melbourne, Australia). The resulting data were analyzed using GenespringGX 7.3.1 (Agilent Technologies, Santa Clara, CA, U.S.A.) as previously described (Dombrecht et al. 2007). Briefly, the raw CEL files were normalized using the RMA algorithm, and then the resulting expression values were normalized per chip to the median across all chips. A two-way analysis of variance was used to investigate differentially expressed genes with a $P$ value cutoff of 0.05 . The microarray data have been submitted to the National Center for Biotechnology Information Gene Expression Omnibus under accession number GSE15236. It should be noted that we have previously reported on a subset of selected genes from this Affymetrix experiment that were differentially expressed between wild-type Col-0 and a pftl mutant in response to $F$. oxysporum inoculations (Kidd et al. 2009) but the analyses of genes that are differentially expressed between $F$. oxysporum-inoculated and control wild-type plants have not been reported previously.

\section{Pathogen inoculations.}

Pathogen inoculations were previously described (Anderson et al. 2004; Campbell et al. 2003; Thatcher et al. 2009). Briefly 3 to 4 weeks of plants at the six- to eight-leaf rosette stage were used in all inoculation experiments, with three replications and 20 to 40 plants used in each replication. F. oxysporum (isolate 5176 provided by R. Shivas from the Queensland Plant Pathology Herbarium, Queensland Primary Industries and Fisheries, 80 Meiers Road, Indooroopilly, Qld 4068, Australia) was maintained on half-strength potato dextrose agar plates. To generate inoculum, $F$. oxysporum was grown in half-strength potato dextrose broth and shaken at $28^{\circ} \mathrm{C}$ for 2 to 3 days. The broth was filtered through Miracloth (Calbiochem, La Jolla, CA, U.S.A.) and the spore solution diluted to a $1 \times 10^{6}$ concentration for inoculations. To inoculate, a root dipping method outlined by Campbell and associates (2003) was used, with the exception that inoculated plants were kept unbagged in long-day (16 h) conditions. The disease severity and percentage of plants showing disease symptoms were assessed 8 to 12 days after inoculations.

\section{TIBA, NPA, NAA, 2,4-D, 6FI, and IAA treatments.}

TIBA (Sigma-Aldrich, St. Louis), NPA (12.5 $\mu \mathrm{M}$, SigmaAldrich), 6-FI (10 $\mu \mathrm{M}$, Sigma-Aldrich), 2,4-D (5 $\mu \mathrm{M}$, SigmaAldrich), NAA (100 $\mu \mathrm{M}$, Sigma-Aldrich), and IAA (20 and 100 $\mu \mathrm{M}$, Sigma-Aldrich) were dissolved in either $0.001 \%$ (wt/vol) ethanol or dimethyl sulfoxide and applied onto soil-grown plants by spraying. For root treatments, these chemicals were mixed with either the inoculum or water and applied either during root inoculations or before inoculations by uprooting the plants and dipping the roots into solutions containing the chemicals. Control plants were mock treated with water containing the same amount of solvent used in dissolving the chemicals.

\section{Fungal transformation.}

A GFP-expressing derivative of $F$. oxysporum strain 5176 was generated by transformation with $p G p d G F P$ (Sexton and Howlett 2001). Protoplasting and transformation were performed as previously described (Desmond et al. 2008), using germlings from microconidia. A red fluorescent strain of $F$. oxysporum was also constructed by Agrobacterium spp.-mediated transformation, as previously described (Mullins et al. 2001). The vector used contained the dTomato gene (Shaner et al. 2004) under the control of the Aspergillus nidulans gpdA promoter and Simian virus 40 (SV40) terminator. To construct this vector, the dTomato fragment was amplified from pRSET-B-dTomato (a gift from R. Tsien, Howard Hughes Medical Institute) using GFPfwd (AATGGTACCATGGTGAGCAAGGGC) and GFPrev (TTACTTGTACAGCTCGTCCATGCC). The SV40 terminator was amplified from $p E G F P-N 1$ (Clontech, Mountain View, CA, U.S.A.) using SV40fwd (GGCATGGACGAGCTGTACAAGTA AAAGCTTTCATAATCAGCCATAC) and SV40rev (GGCGAG CTCATACATTGATGAGTTTG). The resultant fragments were fused using overlap PCR using GFPfwd and SV40rev, and cloned into the KpnI and SacI sites of the pPZPhygHindX (Elliott and Howlett 2006) binary vector conferring resistance to hygromycin. The T4 DNA polymerase-treated KpnI site of this vector was used to insert the Gateway reading frame A cassette from the Gateway Vector conversion kit (Invitrogen, Carlsbad, CA, U.S.A.) to create a destination vector for expression of dTomato in fungi. The gpdA promoter was amplified from pAN7.1 (Punt et al. 1987) using aatB recombination site tailed primers (aatB1-gpdAfwd GGGGACAAGTTTGTACAAAAAAGCAGG CTTAAGACCTAATACAGCCCCT and aatB2-gpdArev GGG GACCACTTTGTACAAGAAAGCTGGGTAAGCCATTGTGA TGTCTGC) and recombined into the dTomato destination vector using a combined BP clonase and LR clonase recombination reaction.

\section{Microscopic analyses.}

Surface sterilized Arabidopsis seed were plated onto halfstrength MS agar with 3\% sucrose and grown vertically in short-day conditions. At the six-leaf stage, morphologically alike plants with similar root systems were transferred to large culture plates of nutrient-free water agar $(\mathrm{pH} \mathrm{8)}$, and the roots were drop inoculated with $1 \mu \mathrm{l}$ of a 1,000 spores/ $\mu$ l suspension of the GFP-expressing $F$. oxysporum isolate. To observe the infection, plants were lifted off the plate and mounted on glass slides and examined under a fluorescent microscope (Axio Scope Zeiss, Oberkochen, Germany).

\section{GUS activity assays.}

For histochemical analysis of GUS activity, DR5:GUS plants inoculated with $F$. oxysporum were submerged in GUS staining buffer containing $1 \mathrm{mM}$ 5-bromo-4-chloro-3-indolyl $\beta$-glucuronidase, $10 \mathrm{nM}$ sodium phosphate $(\mathrm{pH} 7.5), 0.5 \mathrm{mM}$ potassium ferrocyanide, $10 \mathrm{mM}$ EDTA, and $0.1 \%$ Triton $\mathrm{X}$ 100. Seedlings were incubated at $37^{\circ} \mathrm{C}$ in the dark for $3 \mathrm{~h}$ and cleared with $70 \%$ ethanol. In all, 15 and 20 seedlings were used. Quantitative GUS activity was assayed using the substrate 4-methyl umbelliferyl-B-D-glucorinide (Sigma-Aldrich) as previously described by Brown and associates (2003).

\section{ACKNOWLEDGMENTS}

B. N. Kidd is the recipient of a Ph.D. scholarship from the Grains Research and Developmental Collaboration. N. Kadoo and M. Tekeoğlu were the recipients of a BOYSCAST and an Endeavour fellowship, respectively. B. Dombrecht and L. F. Thatcher were the recipients of Office of Chief Executive post-doctoral fellowships. We thank the Arabidopsis Biological Resource Center for the seed of Arabidopsis mutants; T. Guilfoyle for DR5:GUS, D. Cahill and J. Parker for $s g t 1 b, \mathrm{~J}$. Bender for atr2d, atr1-2, 35S:ATR1, and 35S:ATR2, B. Thomma for pad3, J. Celenza and H. Kasahara for cyp79b2cyp79b3, and Syngenta for 35:nahG seed; C. Edgar for providing cDNA samples from infected plants; R. Casu for useful advice on microarray analyses; R. Shivas for the F. oxysporum strain used; T. Fitzgerald, A. Feechan, and S. Tiwari 
for critical manuscript reading; and three anonymous referees for useful comments on the manuscript.

\section{LITERATURE CITED}

Abas, L., Benjamins, R., Malenica, N., Paciorek, T., Wirniewska, J., Moulinier-Anzola, J. C., Sieberer, T., Friml, J., and Luschnig, C. 2006. Intracellular trafficking and proteolysis of the Arabidopsis auxin-efflux facilitator PIN2 are involved in root gravitropism. Nat. Cell. Biol. 8:249-256.

Anderson, J. P., Badruzsaufari, E., Schenk, P. M., Manners, J. M., Desmond, O. J., Ehlert, C., Maclean, D. J., Ebert, P. R., and Kazan, K. 2004. Antagonistic interaction between abscisic acid and jasmonate-ethylene signaling pathways modulates defense gene expression and disease resistance in Arabidopsis. Plant Cell 16:3460-3479.

Bari, R., and Jones, J. D. 2009. Role of plant hormones in plant defense responses. Plant Mol. Biol. 69:473-488.

Barlier, I., Kowalczyk, M., Marchant, A., Ljung, K., and Bhalerao, M. 2000. The SUR2 gene of Arabidopsis thaliana encodes the cytochrome P450 CYP83B1, a modulator of auxin homeostasis. Proc. Natl. Acad. Sci. U.S.A. 97:14819-14824.

Bar-Nun, N., Sachs, T., and Mayer, A. M. 2008. A role for IAA in the infection of Arabidopsis thaliana by Orobanche aegyptiaca. Ann. Bot. 101:261-265.

Bednarek, P., Pislewska-Bednarek, M., Svatos, A., Schneider, B., Doubsky, J., Mansurova, M., Humphry, M., Consonni, C., Panstruga, R., SanchezVallet, A., Molina, A., and Schulze-Lefert, P. 2009. A glucosinolate metabolism pathway in living plant cells mediates broad-spectrum antifungal defense. Science 323:101-106.

Bender, J., and Celenza, J. L. 2009. Indolic glucosinolates at the crossroads of tryptophan metabolism. Phytochem. Rev. 8:25-37.

Bennett, M. J., Marchant, A., Green, H. G., May, S. T., Ward, S. P., Millner, P. A., Walker, A. R., Schulz, B. and Feldmann, K. A. 1996. Arabidopsis AUX1 gene: A permease-like regulator of root gravitropism. Science 273:948-950.

Berrocal-Lobo, M., and Molina, A. 2008. Arabidopsis defense response against Fusarium oxysporum. Trends Plant Sci. 13:145-150.

Berrocal-Lobo, M., Molina, A., and Solano, R. 2002. Constitutive expression of ETHYLENE-RESPONSE-FACTOR1 in Arabidopsis confers resistance to several necrotrophic fungi. Plant J. 29:23-32.

Boerjan, W., Cervera, M. T., Delarue, M., Beeckman, T., Dewitte, W., Bellini, C., Caboche, M., Van Onckelen, H., Van Montagu, M., and Inze, D. 1995. Superroot, a recessive mutation in Arabidopsis, confers auxin overproduction. Plant Cell 7:1405-1419.

Brown, R. L., Kazan, K., McGrath, K. C., Maclean, D. J., and Manners, J. M. 2003. A role for the GCC-box in jasmonate-mediated activation of the PDF1.2 gene of Arabidopsis. Plant Physiol. 132:1020-1032.

Burow, M., Zhang, Z. Y., Ober, J. A., Lambrix, V. M., Wittstock, U., Gershenzon, J., and Kliebenstein, D. J. 2008. ESP and ESM1 mediate indol-3-acetonitrile production from indol-3-ylmethyl glucosinolate in Arabidopsis. Phytochemistry 69:663-671.

Campbell, E. J., Schenk, P. M., Kazan, K., Penninckx, I. A., Anderson, J. P., Maclean, D. J., Cammue, B. P., Ebert, P. R., and Manners, J. M. 2003. Pathogen-responsive expression of a putative ATP-binding cassette transporter gene conferring resistance to the diterpenoid sclareol is regulated by multiple defense signaling pathways in Arabidopsis. Plant Physiol. 133:1272-1284.

Celenza, J. L., Quiel, J. A., Smolen, G. A., Merrikh, H., Silvestro, A. R., Normanly, J., and Bender, J. 2005. The Arabidopsis ATR1 Myb transcription factor controls indolic glucosinolate homeostasis. Plant Physiol. 137:253-262.

Chapman, E. J., and Estelle, M. 2009. Mechanism of auxin-regulated gene expression in plants. Annu. Rev. Genet. 43:265-285.

Chen, Z., Agnew, J. L., Cohen, J. D., He, P., Shan, L., Sheen, J., and Kunkel, B. N. 2007. Pseudomonas syringae type III effector AvrRpt2 alters Arabidopsis thaliana auxin physiology. Proc. Natl. Acad. Sci. U.S.A. 104:20131-20136.

Chini, A., Fonseca, S., Fernandez, G., Adie, B., Chico, J. M., Lorenzo, O., Garcia-Casado, G., Lopez-Vidriero, I., Lozano, F. M., Ponce, M. R., Micol, J. L., and Solano, R. 2007. The JAZ family of repressors is the missing link in jasmonate signaling. Nature 448:666-671.

Clay, N. K., Adio, A. M., Denoux, C., Jander, G., and Ausubel, F. M. 2009. Glucosinolate metabolites required for an Arabidopsis innate immune response. Science 323:95-101.

Consonni, C., Bednarek, P., Humphry, M., Francocci, F., Ferrari, S., Harzen, A., van Themaat, E. V. L., and Panstruga, R. 2010. Tryptophan-derived metabolites are required for antifungal defense in the Arabidopsis mlo2 mutant. Plant Physiol. 152:1544-1561.

Contreras-Cornejo, H. A., Macías-Rodríguez, L., Cortés-Penagos, C., and
López-Bucio, J. 2009. Trichoderma virens, a plant beneficial fungus, enhances biomass production and promotes lateral root growth through an auxin-dependent mechanism in Arabidopsis. Plant Physiol. 149:1579-1592.

Cuzick, A., Maguire, K., and Hammond-Kosack, K. E. 2009. Lack of the plant signalling component SGT1b enhances disease resistance to Fusarium culmorum in Arabidopsis buds and flowers. New Phytol. 181:901-912.

Czymmek, K. J., Fogg, M., Powell, D. H., Sweigard, J., Park, S. Y., and Kang, S. 2007. In vivo time-lapse documentation using confocal and multi-photon microscopy reveals the mechanisms of invasion into the Arabidopsis root vascular system by Fusarium oxysporum. Fungal Genet. Biol. 44:1011-1023.

Delessert, C., Kazan, K., Wilson, I. W., Van Der Straeten, D., Manners, J., Dennis, E. S., and Dolferus, R. 2005. The transcription factor ATAF2 represses the expression of pathogenesis-related genes in Arabidopsis. Plant J. 43:745-757.

Dennis, G., Jr., Sherman, B. T., Hosack, D. A., Yang, J., Gao, W., Lane, H. C., and Lempicki, R. A. 2003. DAVID: Database for annotation, visualization, and integrated discovery. Genome Biol. 4:P3.

Desmond, O. J., Manners, J. M., Stephens, A. E., Maclean, D. J., Schenk, P. M., Gardiner, D. M., Munn, A. L., and Kazan, K. 2008. The Fusarium mycotoxin deoxynivalenol elicits hydrogen peroxide production, programmed cell death and defence responses in wheat. Mol. Plant Pathol. 9:435-445.

Devos, S., Laukens, K., Deckers, P., Van Der Straeten, D., Beeckman, T., Inze, D., Van Onckelen, H., Witters, E., and Prinsen, E. 2006. A hormone and proteome approach to picturing the initial metabolic events during Plasmodiophora brassicae infection on Arabidopsis. Mol. PlantMicrobe Interact. 19:1431-1443.

Dharmasiri, S., Swarup, R., Mockaitis, K., Dharmasiri, N., Singh, S. K., Kowalchyk, M., Marchant, A., Mills, S., Sandberg, G., Bennett, M. J., and Estelle, M. 2006. AXR4 is required for localization of the auxin influx facilitator AUX1. Science 312:1218-1220.

Diener, A. C., and Ausubel, F. M. 2005. RESISTANCE TO FUSARIUM OXYSPORUM 1, a dominant Arabidopsis disease-resistance gene, is not race specific. Genetics 171:305-321.

Dombrecht, B., Kazan, K., and Manners, J. M. 2006. Improved resistance to Fusarium wilt through genetic engineering of defense signaling pathways. Pages 388-398 in: Floriculture, Ornamental and Plant Biotechnology. Global Science Books, London.

Dombrecht, B., Xue, G. P., Sprague, S. J., Kirkegaard, J. A., Ross, J. J., Reid, J. B., Fitt, G. P., Sewelam, N., Schenk, P. M., Manners, J. M., and Kazan, K. 2007. MYC2 differentially modulates diverse jasmonate-dependent functions in Arabidopsis. Plant Cell 19:2225-2245.

Dowd, C., Wilson, I. W., and McFadden, H. 2004. Gene expression profile changes in cotton root and hypocotyl tissues in response to infection with Fusarium oxysporum f. sp. vasinfectum. Mol. Plant-Microbe Interact. 17:654-667.

Edgar, C. I., McGrath, K. C., Dombrecht, B., Manners, J. M., Schenk, P. M., Maclean, D. J., and Kazan, K. 2006. Salicylic acid mediates resistance to the vascular wilt pathogen Fusarium oxysporum in the model host Arabidopsis thaliana. Aust. Plant Pathol. 35:581-591.

Elliott, C. E., and Howlett, B. J. 2006. Overexpression of a 3-ketoacylCoA thiolase in Leptosphaeria maculans causes reduced pathogenicity on Brassica napus. Mol. Plant-Microbe Interact.19:588-596.

Felten, J., Kohler, A., Morin, E., Bhalerao, R. P., Palme, K., Martin, F., Ditengou, F. A., and Legué, V. 2009. The ectomycorrhizal fungus Laccaria bicolor stimulates lateral root formation in poplar and Arabidopsis through auxin transport and signaling. Plant Physiol. 151:19912005.

Friml, J., Wiśniewska, J., Benková, E., Mendgen, K., and Palme, K. 2002. Lateral relocation of auxin efflux regulator PIN3 mediates tropism in Arabidopsis. Nature 415:806-809.

Gigolashvili, T., Berger, B., Mock, H. P., Müller, C., Weisshaar, B., and Flügge, U. I. 2007. The transcription factor HIG1/MYB51 regulates indolic glucosinolate biosynthesis in Arabidopsis thaliana. Plant J. 50:886-901.

Gil, P., Dewey, E., Friml, J., Zhao, Y., Snowden, K. C., Putterill, J., Palme, K., Estelle, M., and Chory, J. 2001. BIG: A calossin-like protein required for polar auxin transport in Arabidopsis. Genes Dev. 15:1985-1997.

Gonzalez, A., Zhao, M., Leavitt, J. M., and Lloyd, A. M. 2008. Regulation of the anthocyanin biosynthetic pathway by the TTG1/bHLH/Myb transcriptional complex in Arabidopsis seedlings. Plant J. 53:814-827.

Gray, W. M., Muskett, P. R., Chuang, H. W., and Parker, J. E. 2003. Arabidopsis SGT1b is required for SCF(TIR1)-mediated auxin response. Plant Cell 15:1310-1319.

Grubb, C. D., and Abel, S. 2006 Glucosinolate metabolism and its control. Trends Plant Sci. 11:89-100.

Grunewald, W., Cannoot, B., Friml, J., and Gheysen, G. 2009a. Parasitic 
nematodes modulate PIN-mediated auxin transport to facilitate infection. PLoS Pathog. 5:e1000266

Grunewald, W., van Noorden, G., Van Isterdael, G., Beeckman, T., Gheysen, G., and Mathesius, U. 2009b. Manipulation of auxin transport in plant roots during Rhizobium symbiosis and nematode parasitism. Plant Cell 21:2553-2562.

Hernández-Blanco, C., Feng, D. X., Hu, J., Sánchez-Vallet, A., Deslandes, L., Llorente, F., Berrocal-Lobo, M., Keller, H., Barlet, X., SánchezRodríguez, C., Anderson, L. K., Somerville, S., Marco, Y., and Molina, A. 2007. Impairment of cellulose synthases required for Arabidopsis secondary cell wall formation enhances disease resistance. Plant Cell 19:890-903

Iavicoli, A., Boutet, E., Buchala, A., and Métraux, J. P. 2003. Induced systemic resistance in Arabidopsis thaliana in response to root inoculation with Pseudomonas fluorescens $\mathrm{CHA} 0$. Mol. Plant-Microbe Interact. 16:851-858

Jones, P., Messner, B., Nakajima, J., Schäffner, A. R., and Saito, K. 2003. UGT73C6 and UGT78D1, glycosyltransferases involved in flavonol glycoside biosynthesis in Arabidopsis thaliana. J. Biol. Chem. 278:43910-43918.

Kariola, T., Brader, G., Li, J., and Palva, E. T. 2005. Chlorophyllase 1, a damage control enzyme, affects the balance between defense pathways in plants. Plant Cell 17:282-294.

Kazan, K., and Manners, J. M. 2008. Jasmonate signaling: Toward an integrated view. Plant Physiol. 146:1459-1468.

Kazan, K., and Manners, J. M. 2009. Linking development to defense: Auxin in plant-pathogen interactions. Trends Plant Sci. 14:373-382.

Kidd, B. N., Edgar, C. I., Kumar, K. K., Aitken, E. A., Schenk, P. M., Manners, J. M., and Kazan, K. 2009. The Mediator complex subunit PFT1 is a key regulator of jasmonate-dependent defense in Arabidopsis. Plant Cell 21:2237-2252.

Knoester, M., Pieterse, C. M., Bol, J. F., and Van Loon, L. C. 1999. Systemic resistance in Arabidopsis induced by rhizobacteria requires ethylene-dependent signaling at the site of application. Mol. Plant-Microbe Interact. 12:720-727.

Krasikov, V., Dekker, H. L., Rep, M., and Takken, F. L. W. 2010. The tomato xylem sap protein XSP10 is required for full susceptibility to Fusarium wilt disease. J. Exp. Bot. 62: 963-973.

Lee, C., Chronis, D., Kenning, C., Peret, B., Hewezi, T., Davis, E. L., Baum, T. J., Hussey, R., Bennett, M., and Mitchum, M. G. 2011. The novel cyst nematode effector protein 19C07 interacts with the Arabidopsis auxin influx transporter LAX3 to control feeding site development. Plant Physiol. 155:866-80.

Lin, R., and Wang, H. 2005. Two homologous ATP-binding cassette transporter proteins, AtMDR1 and AtPGP1, regulate Arabidopsis photomorphogenesis and root development by mediating polar auxin transport. Plant Physiol. 138:949-964.

Llorente, F., Muskett, P., Sánchez-Valleta, A., López, G., Ramos, B., Sánchez-Rodríguez, C., Jordá, L., Parker, J., and Molina, A. 2008. Repression of the auxin response pathway increases Arabidopsis susceptibility to necrotrophic fungi. Mol. Plant 1:496-509.

Lorenzo, O., and Solano, R. 2005. Molecular players regulating the jasmonate signaling network. Curr. Opin. Plant. Biol. 8:532-540.

Lorenzo, O., Piqueras, R., Sanchez-Serrano, J. J., and Solano, R. 2003. ETHYLENE RESPONSE FACTOR1 integrates signals from ethylene and jasmonate pathways in plant defense. Plant Cell 15:165-178.

Lorenzo, O., Chico, J. M., Sanchez-Serrano, J. J., and Solano, R. 2004 Jasmonate-insensitive 1 encodes a MYC transcription factor essential to discriminate between different jasmonate-regulated defense responses in Arabidopsis. Plant Cell 16:1938-1950.

Ludwig-Müller, J. 2009. Glucosinolates and the clubroot disease: Defense compounds or auxin precursors? Phytochem. Rev. 8:135-148.

Ludwig-Müller, J., and Schuller, A. 2008. What can we learn from clubroots: Alterations in host roots and hormone homeostasis caused by Plasmodiophora brassicae. Eur. J. Plant Pathol. 121:291-302.

Ludwig-Müller, J., Prinsen, E., Rolfe, S. A., and Scholes, J. D. 2009. Metabolism and plant hormone action during clubroot disease. J. Plant Growth Regul. 28:229-244.

Ludwig-Müller, J., Denk, K., Cohen, J. D., and Quint, M. 2010. An inhibitor of tryptophan-dependent biosynthesis of indole-3-acetic acid alters seedling development in Arabidopsis. J. Plant Growth Regul. 29:242248

Ma, L. J., van der Does, H. C., Borkovich, K. A., Coleman, J. J., Daboussi, M. J., Di Pietro, A., Dufresne, M., Freitag, M., Grabherr, M., Henrissat, B., Houterman, P. M., Kang, S., Shim, W. B., Woloshuk, C., Xie, X., $\mathrm{Xu}$, J. R., Antoniw, J., Baker, S. E., Bluhm, B. H., Breakspear, A., Brown, D. W., Coutinho, P. M., Danchin, E. G. J., Diener, A., Gale, L., Gardier, D. M., Goff, S., Kammond-Kosak, K. E., Hilburn, K, Hua-Van, A., Jonkers, W., Kazan, K., Kodira, C. D., Koehrsen, M., Kumar, L., Lee, Y. H., Li, L., Manners, J. M., Miranda-Saavedra, D. M., Mukherjee, M.,
Park, G., Park, J., Park, S. Y., Proctor, R. H., Regev, A., Ruiz-Roldan, M. C., Sain, D., Sakthikumar, S., Sykes, S., Schwartz, D. C., Turgeon, B. G., Wapinski, I., Yoder, O., Young, S., Zeng, Q., Zhou, S., Galagan, J., Cuomo, C. A., Kistler, H. C., and Rep, M. 2010. Comparative genomics reveals mobile pathogenicity chromosomes in Fusarium oxysporum. Nature 464:367-373.

McGrath, K. C., Dombrecht, B., Manners, J. M., Schenk, P. M., Edgar, C. I., Maclean, D. J., Scheible, W. R., Udvardi, M. K., and Kazan, K. 2005. Repressor- and activator-type ethylene response factors functioning in jasmonate signaling and disease resistance identified via a genome-wide screen of Arabidopsis transcription factor gene expression. Plant Physiol. 139:949-959.

Michielse, C. B., and Rep, M. 2009. Pathogen profile update: Fusarium oxysporum. Mol. Plant Pathol. 10:311-324.

Millet, Y. A., Danna, C. H., Clay, N. K., Songnuan, W., Simon, M. D. Werck-Reichhart, D., and Ausubel, F. M. 2010. Innate immune responses activated in Arabidopsis roots by microbe-associated molecular patterns. Plant Cell 22:973-990.

Mockaitis, K., and Estelle, M. 2008. Auxin receptors and plant development: A new signaling paradigm. Annu. Rev. Cell. Dev. Biol. 24:55-80.

Mullins, E. D., Chen, X., Romaine, P., Raina, R., Geiser, D. M., and Kang, S. 2001. Agrobacterium-mediated transformation of Fusarium oxysporum: An efficient tool for insertional mutagenesis and gene transfer. Phytopathology 91:173-180.

Navarro, L., Dunoyer, P., Jay, F., Arnold, B., Dharmasiri, N., Estelle, M., Voinnet, O., and Jones, J. D. 2006. A plant miRNA contributes to antibacterial resistance by repressing auxin signaling. Science 312:436-439

Noh, B., Murphy, A. S., and Spalding, E. P. 2001. Multidrug resistancelike genes of Arabidopsis required for auxin transport and auxin-mediated development. Plant Cell 13:2441-2454.

Normanly, J. 2010. Approaching cellular and molecular resolution of auxin biosynthesis and metabolism. Cold Spring Harb. Perspect. Biol 2:a001594.

Okubara, P. A., and Paulitz, T. C. 2005. Root defense responses to fungal pathogens: A molecular perspective. Plant Soil 274:215-226.

Peer, W. A., and Murphy, A. S. 2007. Flavonoids and auxin transport: Modulators or regulators? Trends Plant Sci. 12:556-563.

Péret, B., De Rybel, B., Casimiro, I., Benková, E., Swarup, R., Laplaze, L., Beeckman, T., and Bennett, M. J. 2009. Arabidopsis lateral root development: An emerging story. Trends Plant Sci. 14:399-408.

Pré, M., Atallah, M., Champion, A., De Vos, M., Pieterse, C. M., and Memelink, J. 2008. The AP2/ERF domain transcription factor ORA59 integrates jasmonic acid and ethylene signals in plant defense. Plant Physiol. 147:1347-1357.

Punt, P. J., Oliver, R. P., Dingemanse, M. A., Pouwels, P. H., and van den Hondel, C. A. M. J. J. 1987. Transformation of Aspergillus based on the hygromycin B resistance marker from Escherichia coli. Gene 56:117124.

Ramakers, C., Ruijter, J. M., Deprez, R. H. L., and Moorman, A. F. M. 2003. Assumption-free analysis of quantitative real-time polymerase chain reaction (PCR) data. Neurosci. Lett. 339:62-66.

Ren, C., Pan, J., Peng, W., Genschik, P., Hobbie, L., Hellmann, H., Estelle, M., Gao, B., Peng, J., Sun, C., and Xie, D. 2005. Point mutations in Arabidopsis Cullin1 reveal its essential role in jasmonate response. Plant J. 42:514-524.

Roman, G., Lubarsky, B., Kieber, J. J., Rothenberg, M., and Ecker, J. R. 1995. Genetic analysis of ethylene signal transduction in Arabidopsis thaliana: Five novel mutant loci integrated into a stress response pathway. Genetics 139:1393-1409.

Sanchez-Vallet, A., Ramos, B., Bednarek, P., López, G., PiślewskaBednarek, M., Schulze-Lefert, P., and Molina, A. 2010. Tryptophan-derived secondary metabolites in Arabidopsis thaliana confer non-host resistance to necrotrophic Plectosphaerella cucumerina fungi. Plant J. 63:115-127.

Santelia, D., Henrichs, S., Vincenzetti, V., Sauer, M., Bigler, L., Klein, M., Bailly, A., Lee, Y., Friml, J., Geisler, M., and Martinoia, E. 2008. Flavonoids redirect PIN-mediated polar auxin fluxes during root gravitropic responses. J. Biol. Chem. 283:31218-31226.

Schenk, P. M., Kazan, K., Rusu, A. G., Manners, J. M., and Maclean, D. J. 2005. The SEN1 gene of Arabidopsis is regulated by signals that link plant defense responses and senescence. Plant Physiol. Biochem. 43:997-1005.

Schlaeppi, K., Abou-Mansour, E., Buchala, A., and Mauch, F. 2010. Disease resistance of Arabidopsis to Phytophthora brassicae is established by the sequential action of indole glucosinolates and camalexin. Plant $\mathrm{J}$. 62:840-851.

Segura, A., Moreno, M., and García-Olmedo, F. 1993. Purification and antipathogenic activity of lipid transfer proteins (LTPs) from the leaves of Arabidopsis and spinach. FEBS (Fed. Eur. Biochem. Soc.) Lett. 332:243-246. 
Sexton, A. C., and Howlett, B. J. 2001. Green fluorescent protein as a reporter in the Brassica-Leptosphaeria maculans interaction. Physiol. Mol. Plant Pathol. 58:13-21.

Shaner, N. C., Campbell, R. E., Steinbach, P. A., Giepmans, B. N. G., Palmer, A. E., and Tsien, R. Y. 2004. Improved monomeric red, orange and yellow fluorescent proteins derived from Discosoma sp. red fluorescent protein. Nat. Biotechnol. 22:1567-1572.

Sherameti, I., Venus, Y., Drzewiecki, C., Tripathi, S., Dan, V. M., Nitz, I., Varma, A., Grundler, F. M., and Oelmüller, R. 2008. PYK10, a betaglucosidase located in the endoplasmatic reticulum, is crucial for the beneficial interaction between Arabidopsis thaliana and the endophytic fungus Piriformospora indica. Plant J. 54:428-439.

Siemens, J., Keller, I., Sarx, J., Kunz, S., Schuller, A., Nagel, W., Schmülling, T., Parniske, M., and Ludwig-Müller, J. 2006. Transcriptome analysis of Arabidopsis clubroots indicate a key role for cytokinins in disease development. Mol. Plant-Microbe Interact. 19:480494

Siemens, J., Glawischnig, E., and Ludwig-Müller, J. 2008. Indole glucosinolates and camalexin do not influence the development of the clubroot disease in Arabidopsis thaliana. J. Phytopathol. 156:332-337.

Skirycz, A., Reichelt, M., Burow, M., Birkemeyer, C., Rolcik, J., Kopka, J., Zanor, M. I., Gershenzon, J., Strnad, M., Szopa, J., Mueller-Roeber, B., and Witt, I. 2006. DOF transcription factor AtDof1.1 (OBP2) is part of a regulatory network controlling glucosinolate biosynthesis in Arabidopsis. Plant J. 47:10-24.

Smolen, G. A., Pawlowski, L., Wilensky, S. E., and Bender, J. 2002 Dominant alleles of the basic helix-loop-helix transcription factor ATR2 activate stress-responsive genes in Arabidopsis. Genetics 161:1235-1246.

Sugawara, S., Hishiyama, S., Jikumaru, Y., Hanada, A., Nishimura, T., Koshiba, T., Zhao, Y., Kamiya, Y., and Kasahara, H. 2009. Biochemical analyses of indole-3-acetaldoxime-dependent auxin biosynthesis in Arabidopsis. Proc. Natl. Acad. Sci. U.S.A. 106:5430-5435.

Sun, J., Xu, Y., Ye, S., Jiang, H., Chen, Q., Liu, F., Zhou, W., Chen, R., Li, X., Tietz, O., Wu, X., Cohen, J. D., Palme, K., and Li, C. 2009. Arabidopsis ASA1 is important for jasmonate-mediated regulation of auxin biosynthesis and transport during lateral root formation. Plant Cell 21:1495-1511.

Thaler, J. S., Owen, B., and Higgins, V. J. 2004. The role of the jasmonate response in plant susceptibility to diverse pathogens with a range of lifestyles. Plant Physiol. 135:530-538.

Thatcher, L. F., Manners, J. M., and Kazan, K. 2009. Fusarium oxysporum hijacks COI1-mediated jasmonate signaling to promote disease development in Arabidopsis. Plant J. 58:927-939.

Thines, B., Katsir, L., Melotto, M., Niu, Y., Mandaokar, A., Liu, G. H., Nomura, K., He, S. Y., Howe, G. A., and Browse, J. 2007. JAZ repressor proteins are targets of the SCFCOI1 complex during jasmonate signaling. Nature 448:661-665.

Tierens, K. F., Thomma, B. P., Brouwer, M., Schmidt, J., Kistner, K., Porzel, A., Mauch-Mani, B., Cammue, B. P., and Broekaert, W. F. 2001
Study of the role of antimicrobial glucosinolate-derived isothiocyanates in resistance of Arabidopsis to microbial pathogens. Plant Physiol. 125:1688-1699.

Titapiwatanakun, B., and Murphy, A. S. 2009. Post-transcriptional regulation of auxin transport proteins: Cellular trafficking, protein phosphorylation, protein maturation, ubiquitination, and membrane composition $\mathrm{J}$. Exp. Bot. 60:1093-1107.

Tör, M., Gordon, P., Cuzick, A., Eulgem, T., Sinapidou, E., Mert-Türk, F. Can, C., Dangl, J. L., and Holub, E. B. 2002. Arabidopsis SGT1b is required for defense signaling conferred by several downy mildew resistance genes. Plant Cell 14:993-1003.

Truman, W. M., Bennett, M. H., Turnbull, C. G., and Grant, M. R. 2010. Arabidopsis auxin mutants are compromised in systemic acquired resistance and exhibit aberrant accumulation of various indolic compounds. Plant Physiol. 152:1562-1573.

Ulmasov, T., Murfett, J., Hagen, G., and Guilfoyle, T. J. 1997. Aux/IAA proteins repress expression of reporter genes containing natural and highly active synthetic auxin response elements. Plant Cell 9:19631971

Uppalapati, S. R., Ishiga, Y., Ryu, C. M., Ishiga, T., Wang, K., Noël, L. D., Parker, J. E., and Mysore, K. S. 2011. SGT1 contributes to coronatine signaling and Pseudomonas syringae pv. tomato disease symptom development in tomato and Arabidopsis. New Phytol. 189:83-93.

van Dam, N. M., Tytgat, T. O. G., and Kirkegaard, J. A. 2009. Roots and shoot glucosinolates: A comparison of their diversity, function and interactions in natural and managed ecosystems. Phytochem. Rev. 8:171186.

van Hemelrijck, W., Wouters, P. F. W., Brouwer, M., Windelinckx, A., Goderis, I. J. W. M., De Bolle, M. F. C., Thomma, B. P. H. J., Cammue, B. P. A., and Delauré, S. L. 2006. The Arabidopsis defense response mutant esa1 as a model to discover novel resistance traits against Fusarium diseases. Plant Sci. 171:585-595.

Wang, D., Pajerowska-Mukhtar, K., Culler, A. H., and Dong, X. 2007. Salicylic acid inhibits pathogen growth in plants through repression of the auxin signaling pathway. Curr. Biol. 17:1784-1790.

Woodward, A. W., and Bartel, B. 2005. Auxin: Regulation, action, and interaction. Ann. Bot. 95:707-735.

Zhao, Y., Hull, A. K., Gupta, N. R., Goss, K. A., Alonso, J., Ecker, J. R., Normanly, J., Chory, J., and Celenza, J. L. 2002. Trp-dependent auxin biosynthesis in Arabidopsis: Involvement of cytochrome P450s CYP79B2 and CYP79B3. Genes Dev. 16:3100-3112.

Zimmermann, P., Hirsch-Hoffmann, M., Hennig, L., and Gruissem, W. 2004. GENEVESTIGATOR. Arabidopsis microarray database and analysis toolbox. Plant Physiol. 136:2621-2632.

\section{AUTHOR-RECOMMENDED INTERNET RESOURCE}

Gene Expression Omnibus database: www.ncbi.nlm.nih.gov/geo 